\title{
Links between the Big Dry in Australia and hemispheric multi-decadal climate variability - implications for water resource management
}

\author{
D. C. Verdon-Kidd ${ }^{1}$, A. S. Kiem ${ }^{2}$, and R. Moran ${ }^{2}$ \\ ${ }^{1}$ Environmental and Climate Change Research Group, School of Environmental and Life Sciences, University of Newcastle, \\ Callaghan, Australia \\ ${ }^{2}$ Water Group, Department of Environment and Primary Industries, Victoria, Australia
}

Correspondence to: D. C. Verdon-Kidd (danielle.verdon@newcastle.edu.au)

Received: 27 September 2013 - Published in Hydrol. Earth Syst. Sci. Discuss.: 11 November 2013

Revised: - - Accepted: 10 May 2014 - Published: 18 June 2014

\begin{abstract}
Southeast Australia (SEA) experienced a protracted drought during the mid-1990s until early 2010 (known as the Big Dry or Millennium Drought) that resulted in serious environmental, social and economic effects. This paper analyses a range of historical climate data sets to place the recent drought into context in terms of Southern Hemisphere inter-annual to multi-decadal hydroclimatic variability. The findings indicate that the recent Big Dry in SEA is in fact linked to the widespread Southern Hemisphere climate shift towards drier conditions that began in the mid-1970s. However, it is shown that this link is masked because the large-scale climate drivers responsible for drying in other regions of the mid-latitudes since the mid-1970s did not have the same effect on SEA during the mid- to late 1980s and early 1990s. More specifically, smaller-scale synoptic processes resulted in elevated autumn and winter rainfall (a crucial period for SEA hydrology) during the mid- to late 1980s and early 1990s, which punctuated the longer-term drying. From the mid-1990s to 2010 the frequency of the synoptic processes associated with elevated autumn/winter rainfall decreased, resulting in a return to drier than average conditions and the onset of the Big Dry. The findings presented in this paper have marked implications for water management and climate attribution studies in SEA, in particular for understanding and dealing with "baseline" (i.e. current) hydroclimatic risks.
\end{abstract}

\section{Introduction}

\subsection{The Big Dry and other protracted droughts in Australia's history}

Australia, with its naturally highly variable climate, is no stranger to drought conditions. For example, the Federation Drought ( 1895-1902) was associated with drought conditions covering the majority of the eastern two-thirds of Australia (Verdon-Kidd and Kiem, 2009a). From 1937 to 1945 Southeast Australia (SEA) was subjected to another multiyear drought, known as the World War II Drought, while more recently the Big Dry (or Millennium Drought) affected SEA during the mid-1990s through to early 2010 and resulted in a marked reduction in rainfall and runoff (NWC, 2006; Murphy and Timbal, 2008; Verdon-Kidd and Kiem, 2009a, b; Kiem and Verdon-Kidd, 2010; Gallant et al., 2012). In addition to the multi-year droughts mentioned, a number of shorter, equally intense droughts have also occurred during SEA's instrumental history (e.g. 1914-1915, 1965-1968 and 1982-1983).

In terms of annual rainfall deficits the Big Dry has been shown to be more severe in parts of SEA than the earlier multi-year droughts for durations of 3-19 years (CSIRO, 2012); however, the Federation and World War II droughts were more widespread (Verdon-Kidd and Kiem, 2009a). The Big Dry was also characterised by a lack of high 1day rainfall totals (Murphy and Timbal, 2008; Verdon-Kidd and Kiem, 2009a) and wet months (CSIRO, 2012), which is consistent with a reduction in the amount of rainfall 
associated with cut-off low pressure systems over this period (Pook et al., 2006) and an absence of persistent pre-frontal troughs that aid the penetration of rain-producing cold fronts into SEA (Verdon-Kidd and Kiem, 2009b; Alexander et al., 2010). There is considerable debate about the causes of the Big Dry. For example, Verdon-Kidd and Kiem (2009a) attribute the rainfall deficits primarily to the El Niño-Southern Oscillation (ENSO) and the Southern Annular Mode (SAM), while van Dijk et al. (2013) estimate that the latter part of the drought (2001-2009) was driven by ENSO with a small contribution by the Interdecadal Pacific Oscillation (IPO). Others (e.g. Timbal et al., 2010) attribute the drought to an intensification of the Subtropical Ridge.

In 2010/11, a strong La Niña combined with warm sea surface temperatures (SSTs) off northwestern Australia (i.e. a negative Indian Ocean Dipole (IOD) event) resulted in wet austral spring/summer conditions across much of SEA, providing relief from the extended drought. A second La Niña event followed in 2011/12 which resulted in average to above-average rainfall across much of SEA from mid-spring to early autumn, and further replenished water storages.

\subsection{The Big Dry in the context of other Southern Hemisphere droughts}

It has been suggested that the Big Dry in SEA has similarities to the extended dry spell that began in the late 1960s/mid1970s in southwest Western Australia (SWWA) (e.g. Hope et al., 2009; IOCI, 2002) and has continued to the present time, with a possible intensification occurring from the mid1990s (Hope et al., 2006). Indeed, both regions exhibit a common winter-maximum rainfall regime, with peak rainfall occurring from May to October, and rainfall variability (on a synoptic to interannual scale) in the two regions is significantly related, with rainfall during May, June and July being significantly correlated (Hope et al., 2009). However, while both regions have experienced reduced cool season rainfall, the timing with respect to the start of the decreased rainfalls is not consistent. For example, in SWWA average winter (June-August) rainfall totals have decreased by approximately $20 \%$ since the 1970s, while in Victoria the decreased rainfall trend occurred mostly from the mid-1990s, predominantly during late autumn and early winter (a decrease of approximately $20 \%$ during the $1997-2010$ period, relative to the historic average) (e.g. Murphy and Timbal, 2008; Hope et al., 2009; Verdon-Kidd and Kiem 2009a; Gallant et al., 2012). The decreased rainfalls in SWWA have been linked to a reduction in winter storm formation, with the growth rate of the leading storm track modes affecting southern Australia being more than 30\% lower during the period 1975-1994 compared to the period 1949-1968 (Frederiksen et al., 2005, 2007). The differences in timing of the decreases between SWWA and SEA make it unclear as to whether the post-mid1970s SWWA climate shift is related to or independent of the mid-1990s to early 2010 SEA Big Dry.
The mid-1970s corresponds to a period of change in ocean-atmospheric processes of the Pacific Ocean (i.e. ENSO and the Interdecadal Pacific Oscillation (IPO)), which have resulted in more frequent droughts for much of eastern Australia (Power et al., 1999; Kiem and Franks, 2004; Verdon and Franks, 2006). There is also evidence that generalised warming across the Indian Ocean since the mid1970s may be linked to the decreased rainfalls in SWWA (Verdon and Franks, 2005; Samuel et al., 2006). The mid1940s and mid-1920s relate to periods of significant climatic shifts in the Pacific and Indian Ocean regions, highlighting the fact that the mid-1970s climate shift is not an isolated event (Mantua et al., 1997; Power et al., 1999; Kiem et al., 2003; Verdon and Franks, 2006). It has also been shown that inter-annual to multi-decadal variability not only affects Australia, with numerous studies identifying similar dry and wet epochs in other regions of the Southern Hemisphere. For example, a regime shift in New Zealand's climate around 1976 has also been identified (Salinger and Mullan, 1999), with the 1976-1994 period characterised by annual rainfall decreases in the north of the North Island, and increases in much of the South Island, except the east. An earlier shift in New Zealand's climate was also observed in the early 1950s, where the period 1951-1975 was characterised by increased rainfall in the north of the North Island, particularly in autumn, with rainfall decreases in the southeast of the South Island, especially in summer (Salinger and Mullan, 1999). In southern Africa, overall moist conditions were reported between 1960 and 1970 and since then a switch to drier conditions has been noted (Ngongondo, 2006). Western Africa (in the Northern Hemisphere), which regularly experiences protracted drought conditions, has also experienced an extreme drought known as "the Sahel Drought" beginning in the 1970s (Hulme, 1992), continuing to the present. Recent research by Van Ommen and Morgan (2010) reported a significant inverse correlation between the records of precipitation at Law Dome, East Antarctica and SWWA over the instrumental period. In particular, since the mid-1970s rainfall has increased at Law Dome, while rainfall has decreased in SWWA.

The apparent connection between rainfall in SWWA and East Antarctica, along with the similar timing of climate shifts in southern Africa and New Zealand, provides evidence to suggest synchronicity in climate shifts occurs in the Southern Hemisphere (a concept that has recently been analysed by Verdon-Kidd and Kiem, 2013). These observations also highlight the presence of climate phases/cycles that operate over multi-decadal timescales. Yet it is still unclear how/if the Big Dry in SEA is related to these hemispheric changes. 


\subsection{Managing the Big Dry and future water availability of the SEA region}

Resource managers in the water and agricultural sectors across SEA have a long history of dealing with climate variability. During the early to mid-1990s, at both the national and state level, significant effort went into ensuring drought preparedness and the development of effective drought response strategies. However, the unprecedented severity and duration of the Big Dry "stress-tested" these processes. In terms of the water entitlement, and water planning and management framework in Victoria, existing drought response processes served well during the early part of the drought. However, 2006 saw the lowest flows on record across most of the state and, from 2006 to 2009, additional contingency measures were required in some situations to ensure that essential water needs were met. These measures included water carting, groundwater bores, pumping from dead storage, qualification of rights to water, and changes to water sharing arrangements and water trading rules. In addition, the Victorian Government and water corporations invested in infrastructure and in water efficiency and conservation measures to augment supplies (DSE, 2011).

Recent research conducted under the South Eastern Australian Climate Initiative indicates that, while the Big Dry has broken, rainfall deficits during the cool season (AprilOctober), which is the traditional filling season for water storages, have tended to persist (CSIRO, 2012). This persistent rainfall deficit has been shown to be associated with changes in the global atmospheric circulation via the expansion of the Hadley circulation (estimated at $50 \mathrm{~km}$ per decade) and associated increase in pressure in the subtropical ridge, resulting in mid-latitude storm tracks being "pushed" further south (CSIRO, 2012; Whan et al., 2014). Cai et al. (2012) also related the observed expansion of the Hadley Cell to a poleward progression of the tropical belt and subtropical dry zone, which they claim can explain most of the southeastern Australian rainfall decline. The expansion of the Hadley Cell can only be reproduced by global climate models when human influences (in the form of greenhouse gases, aerosols and stratospheric ozone) are included, leading to the assertion that the expansion is at least partially attributed to anthropogenic climate change (CSIRO, 2012; Lucas et al., 2012). However, the exact cause of the expansion is highly debated. The width of the Hadley circulation is determined by the tropical tropopause height, pole-equator temperature difference and the global mean radiative equilibrium temperature ( $\mathrm{Hu}$ and $\mathrm{Fu}, 2007)$. Each anthropogenic factor (i.e. greenhouse gases, aerosols and stratospheric ozone) impacts differently upon these dynamics - making it difficult to determine the relative importance of each. Model projections indicate that these trends are likely to continue, although the models tend to underestimate observed trends (e.g. Lu et al., 2007; CSIRO, 2012). There are therefore significant uncertainties about the timing and magnitude of associated reduc- tions in mid-latitude rainfall. The overall implication, nevertheless, is that the traditional filling season for water supply systems across most of SEA, which historically was considered to run from about May to November, may not be as reliable in the future. Rather, replenishment of storages may in the future be more dependent on warm season rainfall events which, in turn, will primarily depend on the status of the El Niño-Southern Oscillation (ENSO), the IOD and the Southern Annular Mode (SAM) (Verdon-Kidd and Kiem, 2009b; Gallant et al., 2012). However, future changes in these key climate influences (in particular ENSO) are also not certain, and it is unclear to what extent continuing reductions in cool season rainfall are likely to be offset by higher warm season rainfalls (which also suffer from higher evaporative losses). Without this understanding it is difficult to plan for future water availability in the region. For example, do we need to change the "baseline" estimation of climate to reflect an overall "new" drier climate state?

In the light of the experiences during the Big Dry and the significant uncertainties currently associated with future climate, adaptive management principles have been built into the water management and planning framework across SEA, and water trading arrangements have been modified to assist in maintaining reliable water supplies in the face of a variable and changing climate (see for example McMahon et al., 2008; DSE, 2011; www.nccarf.edu.au/content/robustoptimization-urban-drought).

For example, in Victoria, prior to the Big Dry, the framework for maintaining an acceptable reliability of water supplies required water corporations to develop long-term strategies (aimed at balancing supply and demand over the next 50 years) and complementary short-term drought response plans (aimed at managing short-term deficits in supply) for each of the supply systems under their control. The flow scenarios considered over the 50-year time frame included the continuation of historic conditions and low, medium and high climate change flow projections out 50 years. These strategies were reviewed and updated every 5 years. As a consequence of the Big Dry, the possibility of the conditions of the drought returning in the immediate future, and persisting, is an additional scenario that is considered in long- and shortterm planning processes. Given that flow reductions during the Big Dry exceeded medium to high climate change projections out to 2060, this means that a wide range of possible futures are considered. Water corporations are now also required to develop (in November every year) annual water security outlooks over a 1-5 year time frame using a range of possible future flow scenarios and, in the light of an associated risk assessment, make decisions as to whether to implement any of the short- or long-term options to reduce demand and/or augment supplies. Water trading arrangements have also been modified to allow users to take allocations that are unused at the end of a season into the following season. This provides all water users - irrigators, urban water corporations, and environmental managers - with greater flexibility 
to manage their own water availability. All these measures help ensure an appropriate and timely response to variable and changing climatic conditions.

\subsection{Objectives}

This paper aims to establish if the Big Dry that impacted SEA from the mid-1990s to 2010 is related to the 1970s climate shift experienced in many regions of the Southern Hemisphere (Sect. 3), and in particular the step change in climate observed in SWWA (Sect. 4). The synoptic processes that contribute to the differences observed in SWWA and SEA since the 1970s are explored in Sect. 5, while the role of remote large-scale drivers are analysed in Sect. 6. Implications of the findings for water resource management in the region are analysed and discussed in Sect. 7 of the paper.

\section{Data}

\subsection{Gridded climate data}

The daily NCEP/NCAR (National Centres for Environmental Prediction and the National Centre for Atmospheric Research) Reanalysis global gridded data sets (available 1948present), from the US National Oceanic and Atmospheric Administration (NOAA, www.esrl.noaa.gov/psd/), are used to identify various synoptic patterns that influence the rainfall of SEA and to develop an understanding of Southern Hemisphere climatology during different climate epochs. The NCEP/NCAR Reanalysis data is derived from a global spectral model with a grid resolution of 2.5 degree latitude $\times 2.5$ degree longitude global $(144 \times 73$ grids $)$. As with all reanalysis data, this data has various limitations, particularly in the Southern Hemisphere where historical recorded data tends to be sparse. Trenberth and Guillemot (1998) provide a review of limitations associated with the NCEP/NCAR reanalysis data, in particular the uncertainties inherent in the atmospheric moisture representation.

Gridded monthly precipitation data for Australia was obtained from the Australian Water Availability Project (AWAP), a joint initiative of the Bureau of Meteorology (BoM) and the Commonwealth Scientific and Industrial Research Organisation (CSIRO). In the daily/monthly AWAP data set the observed daily/monthly rainfall from gauges within the BoM gauging network (i.e. up to approximately 7500 gauges, both open and closed) are decomposed into a monthly average and associated anomaly (Jones et al., 2009). The daily/monthly anomalies are interpolated using the Barnes successive correction technique, and the monthly climatological averages are interpolated using three dimensional smoothing splines (Jones et al., 2009). The rainfall grids are produced by multiplying the monthly climate average grids and daily/monthly anomaly grids. An unexplained microscale variance term is used in AWAP to allow for observational or measurement error, such that exact reproduc-

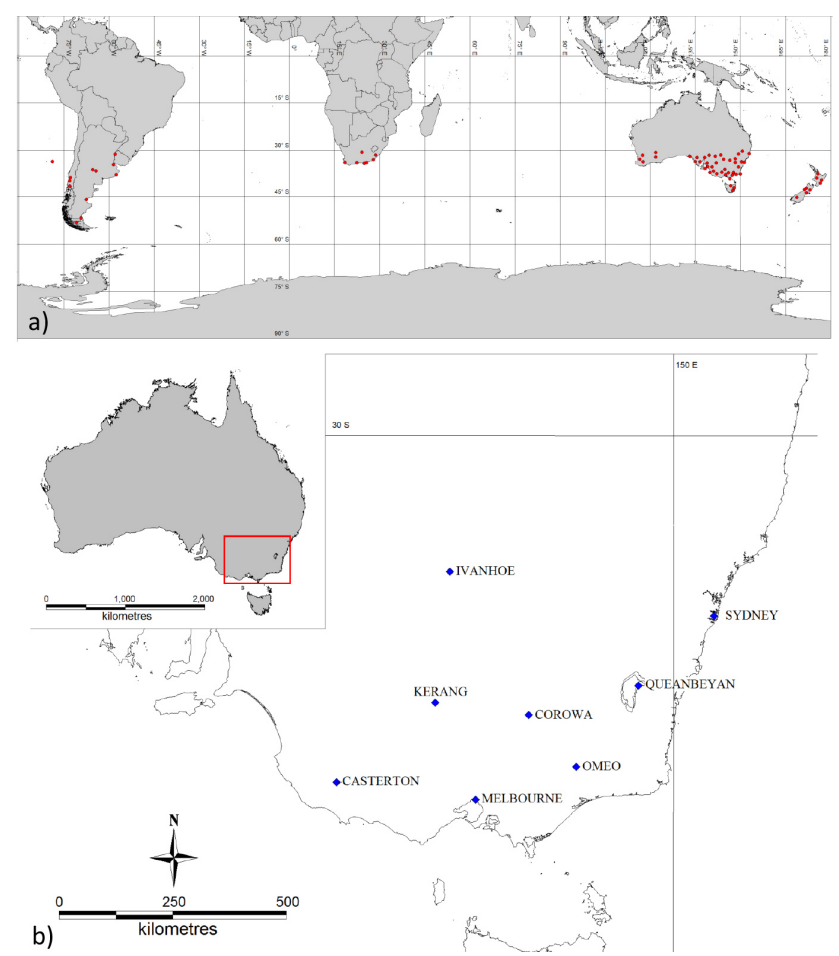

Figure 1. Location of (a) monthly rainfall stations (red circles) and (b) eight high-quality daily rainfall stations in SEA (blue diamonds). Note monthly station data varies in length with all stations containing data from at least 1920 to 2009 (with the exception of two stations from Argentina that include data from 1931 onwards, which were included in order to improve the spatial coverage of the east coast of South America).

tion of gauged values at each gauge location is not expected (Jones et al., 2009). AWAP rainfall grids are freely available from 1900 onwards at http://www.bom.gov.au/jsp/awap/.

\subsection{Station-based rainfall data}

The dry conditions during the Big Dry were largely confined to regions south of 30 degrees (Verdon-Kidd and Kiem, 2009a). Therefore, in order to provide a spatial/geographical context to the recent dry conditions in SEA, and to ensure limitations of gridded rainfall data sets are not skewing our results (see Tozer et al., 2012), station-based rainfall data from regions south of 30 degrees (shown in Fig. 1a) from the following data sets was also used:

- Australia - Monthly station-based rainfall data was obtained from the Australian Bureau of Meteorology (www.bom.gov.au/climate/data/weather-data. shtml). Data chosen for analysis was at least $95 \%$ complete and covered the period 1900-2009. Daily rainfall data was also obtained for eight stations located in SEA (see Fig. 1b) in order to further investigate the daily characteristics of the monthly rainfall totals (i.e. number of rain days, daily rainfall magnitude etc.). The stations 


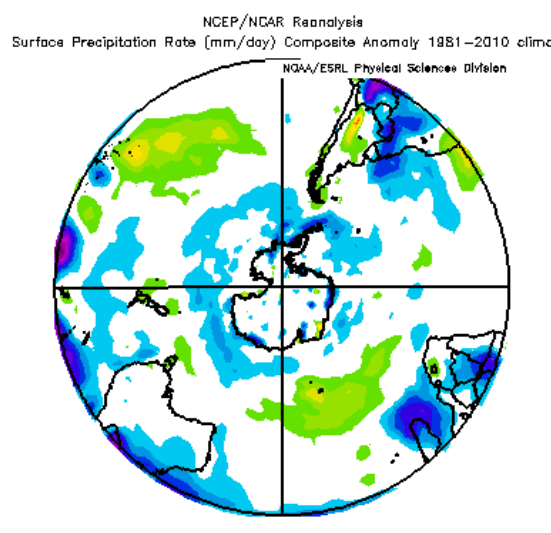

Jan to Dec: 1994 to 2009 minus 1946 to 1993

a)

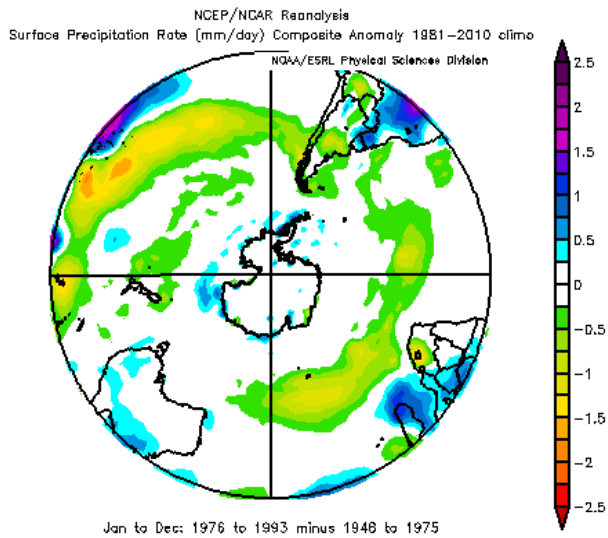

c)

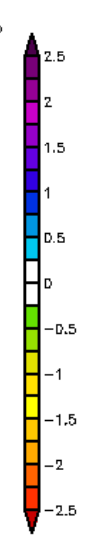

b)
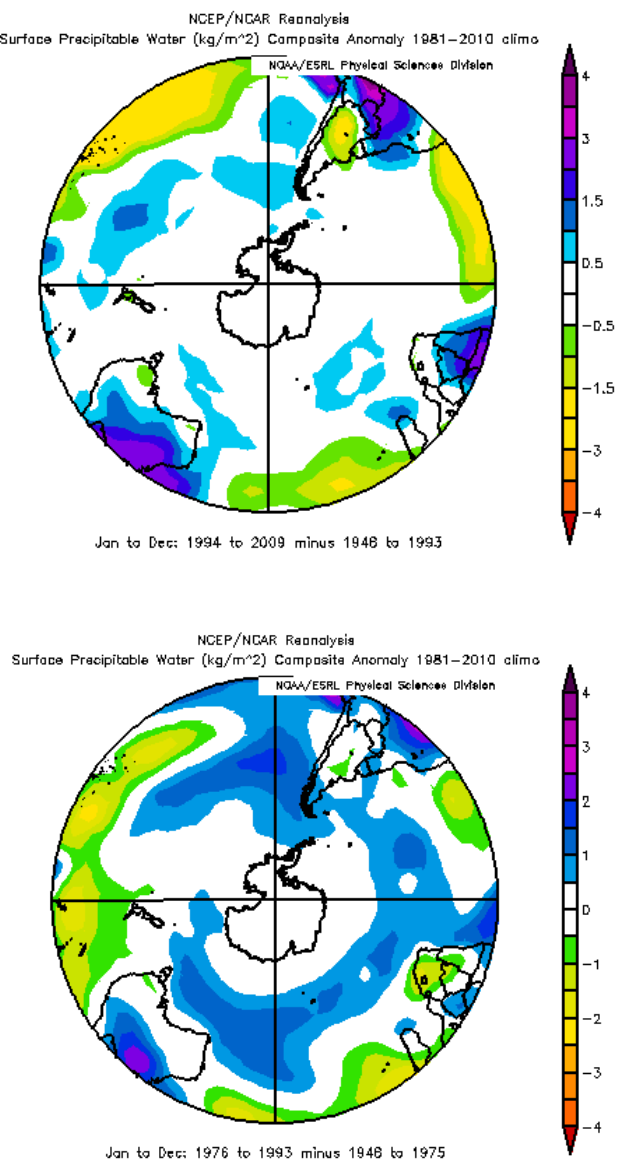

d)

Figure 2. Difference in annual (a) surface precipitation rate (1994-2009 compared to 1948-1993), (b) precipitable water (1994-2009 compared to 1948-1993), (c) surface precipitation rate (1976-1993 compared to 1948-1975) and (d) precipitable water (1976-1993 compared to $1948-1975)$.

chosen for analysis have sufficiently long records (i.e. at least 100 years) and minimal missing data (at least $99 \%$ complete).

- New Zealand - Daily station data was obtained from the National Climate Database of the National Institute of Water and Atmospheric Research (NIWA, http:// cliflo.niwa.co.nz/). Data chosen for analysis was at least $95 \%$ complete and covered the period 1920-present. An additional station was chosen for analysis (located at Reefton on the west coast of New Zealand) that contained daily data from 1948 onwards in order to sufficiently represent the west coast of New Zealand, since the climatology there differs significantly from the east coast. Daily data was aggregated to monthly data prior to analysis.

- South America and southern Africa - Monthly rainfall data for South America and southern Africa was obtained from the Global Historical Climatol- ogy Network (GHCN, www.ncdc.noaa.gov/oa/climate/ ghcn-monthly/index.php). The historical GHCN data has previously undergone rigorous quality assurance review (including pre-processing checks on source data, time series checks that identify spurious changes in the mean and variance, spatial comparisons that verify the accuracy of the climatological mean and the seasonal cycle, and neighbour checks that identify outliers from both a serial and a spatial perspective). GHCN-Monthly is used operationally by NCDC to monitor long-term trends in temperature and precipitation. It has also been employed in several international climate assessments, including the Arctic Climate Impact Assessment, and the "State of the Climate" report published annually by the Bulletin of the American Meteorological Society.

Despite the level of quality assurance, the rainfall data available through the GHCN for South America and southern Africa is not as complete as data from Australia and New Zealand, with the more recent data being particularly sparse, 

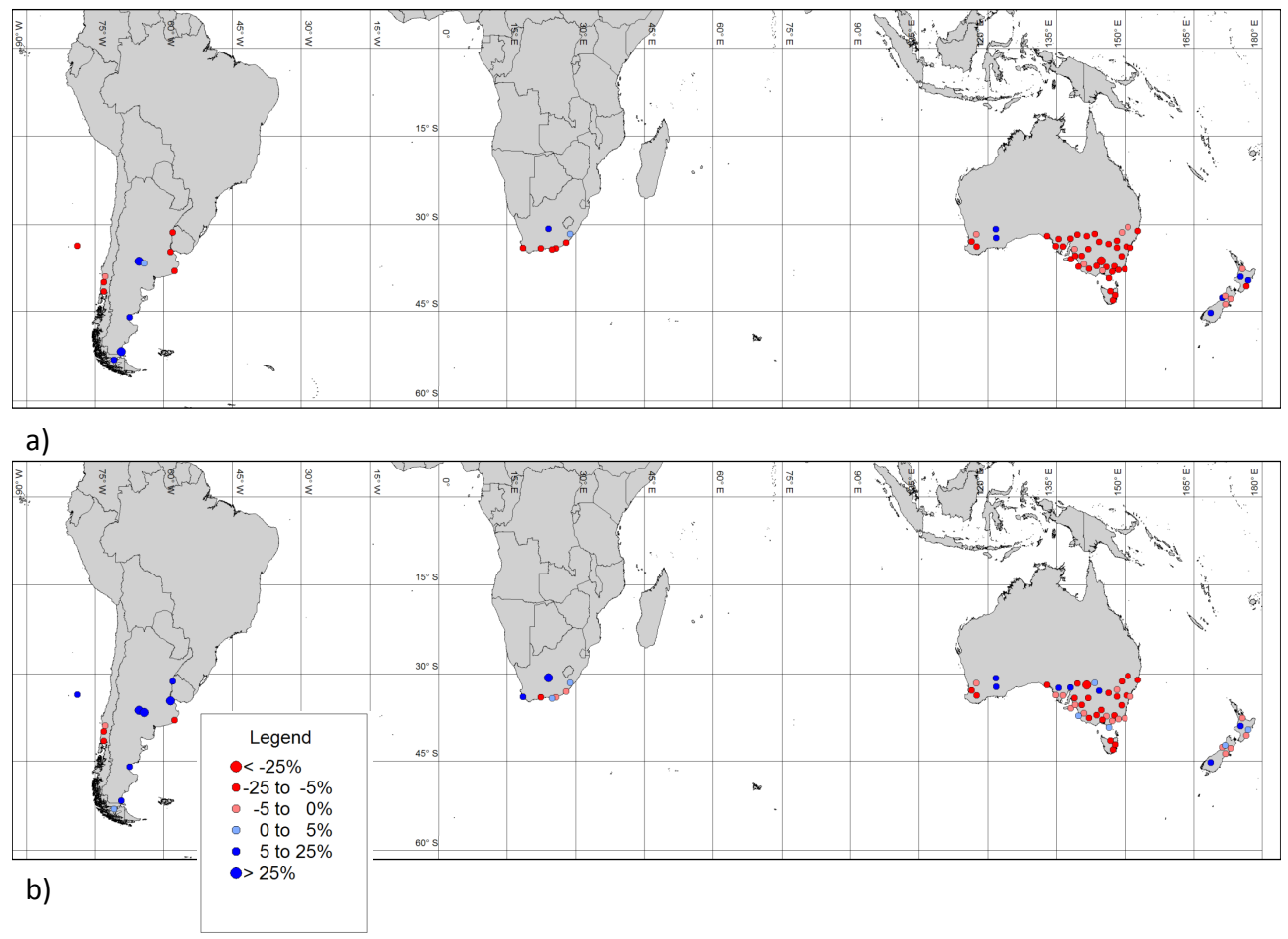

Figure 3. Difference in station-based rainfall (shown as a percentage change) for the period (a) 1994-2009 compared to 1948-1993, (b) 1976-1993 compared to 1948-1975.

especially in southern Africa and South America. Given that the main focus of this study is on the 15 years up to 2009 (i.e. period covered by the Big Dry) and that only stations with complete data over this period were included in our analysis, the spatial coverage of the station-based rainfall data is poor in some regions (see Fig. 1).

\section{Setting the context of recent dry conditions in SEA in terms of Southern Hemisphere variability}

While it is well known that SEA experienced a prolonged drought from the mid-1990s to early 2010 (e.g. NWC, 2006; Murphy and Timbal, 2008; Verdon-Kidd and Kiem, 2009a, b; Kiem and Verdon-Kidd, 2010; Gallant et al., 2012), it is unclear if other regions of similar latitude also experienced a step change in climate (either too dry or wet) at this time. The NCEP/NCAR Reanalysis data sets described in Sect. 2.1 were used to study this as a first step towards identifying possible climate linkages in the Southern Hemisphere during this period. Figure 2a and b show, for the Southern Hemisphere, the annual difference in surface precipitation rate and precipitable water, respectively, during the period 1994-2009 compared to the period 1948-1993 (note that 1994 was used as a starting year for the drought as per the findings of Kiem and Verdon-Kidd (2010); 1948 was used as the start of the analysis period, as this is restricted by the NCEP/NCAR data set). As discussed in the Introduction, it is well known that the rainfall decline in SWWA began as early as the late 1960s/mid-1970s (IOCI, 2002; Hope et al., 2009), which corresponds to a time of significant changes in the climate system in the Southern Hemisphere. Therefore, it is possible that any drying trends observed from 1994-2009 are part of a continuation from an earlier step change in climate. To examine this, the precipitation rate and precipitable water analysis was also repeated for the period 1976-1993 (i.e. the period prior to the mid-1990s step change in SEA) as shown in Fig. 2c and d, respectively. The year 1976 was chosen as the start year of this analysis, as this corresponds to a statistically significant change in ocean/atmosphere processes and a reorganisation of the climate system (Mantua et al., 1997).

Tozer et al. (2012), and other references reviewed within, demonstrate that gridded rainfall data sets often do not capture extreme events particularly well (due to smoothing during the interpolation process, inadequate representation of topographical effects, uncertainties associated with remotely sensed data, density of available station data that varies in space and time, etc.). Further, as mentioned in Sect. 2.2, rainfall data observations for the Southern Hemisphere tend to be sparser than the Northern Hemisphere, particularly for regions such as South America, southern Africa and Antarctica. Therefore, in order to ground truth the observations made using the gridded data set, the station-based monthly rainfall data (described in Sect. 2.2) was also used to compare rainfall during the period 1994-2009 with the period 


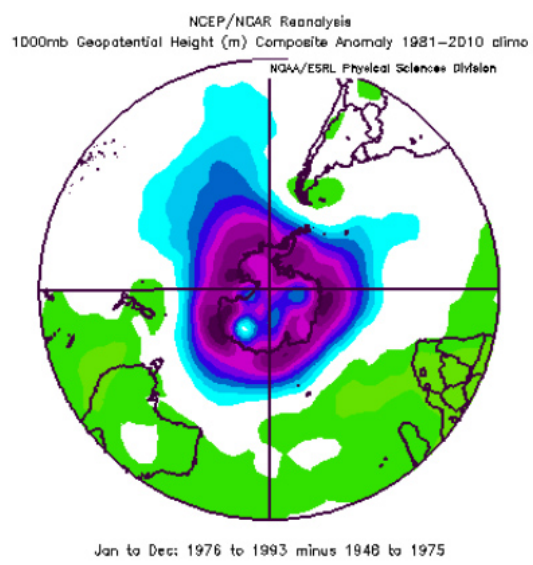

a)

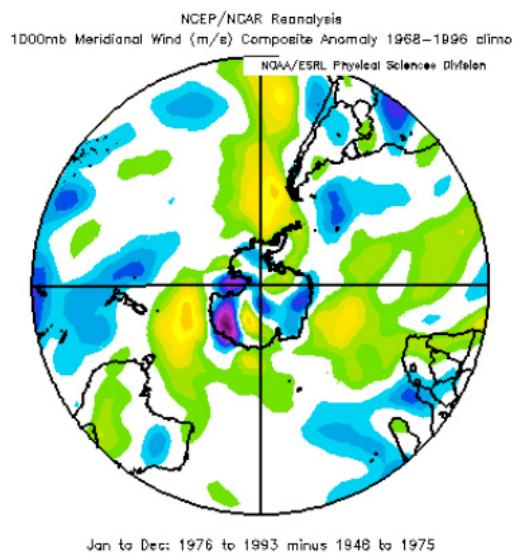

c)
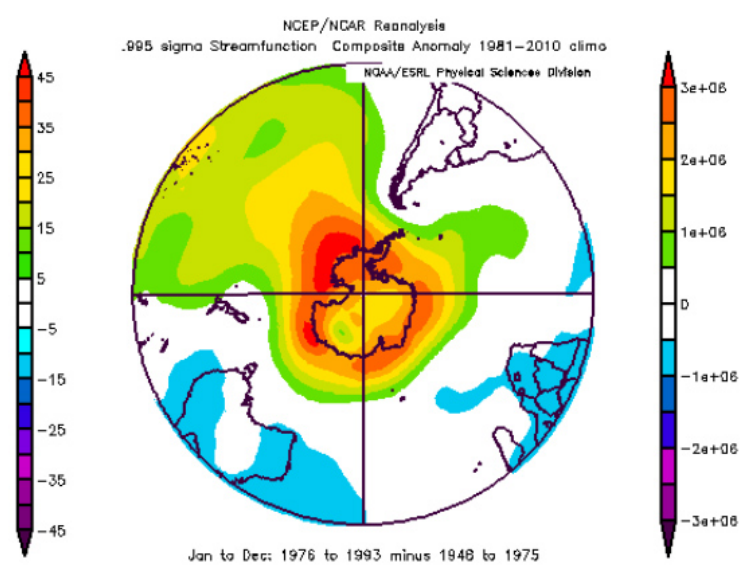

b)
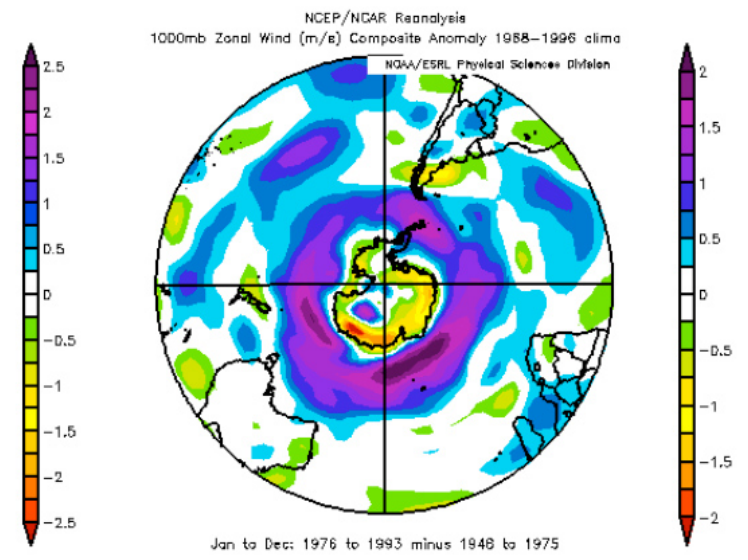

d)

Figure 4. Difference in annual (a) geopotential height, (b) streamfunction, (c) meridional and (d) zonal wind anomalies during the period 1976-1993 compared to 1948-1975.

1948-1993 (the period which the NCEP/NCAR data covers) and the period 1976-1993 to 1948-1975 (to investigate the possibility of an earlier step change). The results are shown in Fig. 3.

Figure $2 \mathrm{a}$ and $\mathrm{b}$ show that, for the period 1994-2009, there was a clear increase in the surface precipitation rate and precipitable water relative to 1948-1993 in the northwest of Australia, the northeast and northwest of South America and the northwest of southern Africa. Figure 2a and b also show a corresponding decrease in precipitation during this period in the southwest and southeast of Australia, New Zealand and central South America. Further, the station-based data (Fig. 3a) support the findings above, providing multiple lines of evidence (from three data sets) that, since the mid-1990s, there appears to be a southward migration of rain-bearing systems in the Southern Hemisphere, resulting in a dry band across approximately $30-45^{\circ} \mathrm{S}$ (consistent with the findings of CSIRO, 2012).
The analysis presented here also suggests that the trends in precipitation across the Southern Hemisphere observed in the post-1994 analysis are likely to be part of a longer-term trend beginning around the mid-1970s, given the similarity in the anomaly patterns (Figs. 2c, 2d and 3b) between the two time slices (for regions other than SEA). Figure 4a clearly shows a reduction in geopotential height since the mid-1970s over Antarctica (indicating an increase in conditions conducive to storms) and a corresponding increase in geopotential height over Australia, southern Africa and New Zealand (associated with clear weather). Similarly, Fig. 4b shows an intensification of streamfunction over Antarctica and the southern oceans and a decrease over Australia and southern Africa, further evidence of a southward migration of storm tracks over this period. Figure $4 \mathrm{~b}$ and $\mathrm{c}$ confirm that there has also been a corresponding decrease in meridional winds south of 30 degrees and an increase in zonal winds since the mid1970s. These observations are consistent with the findings 

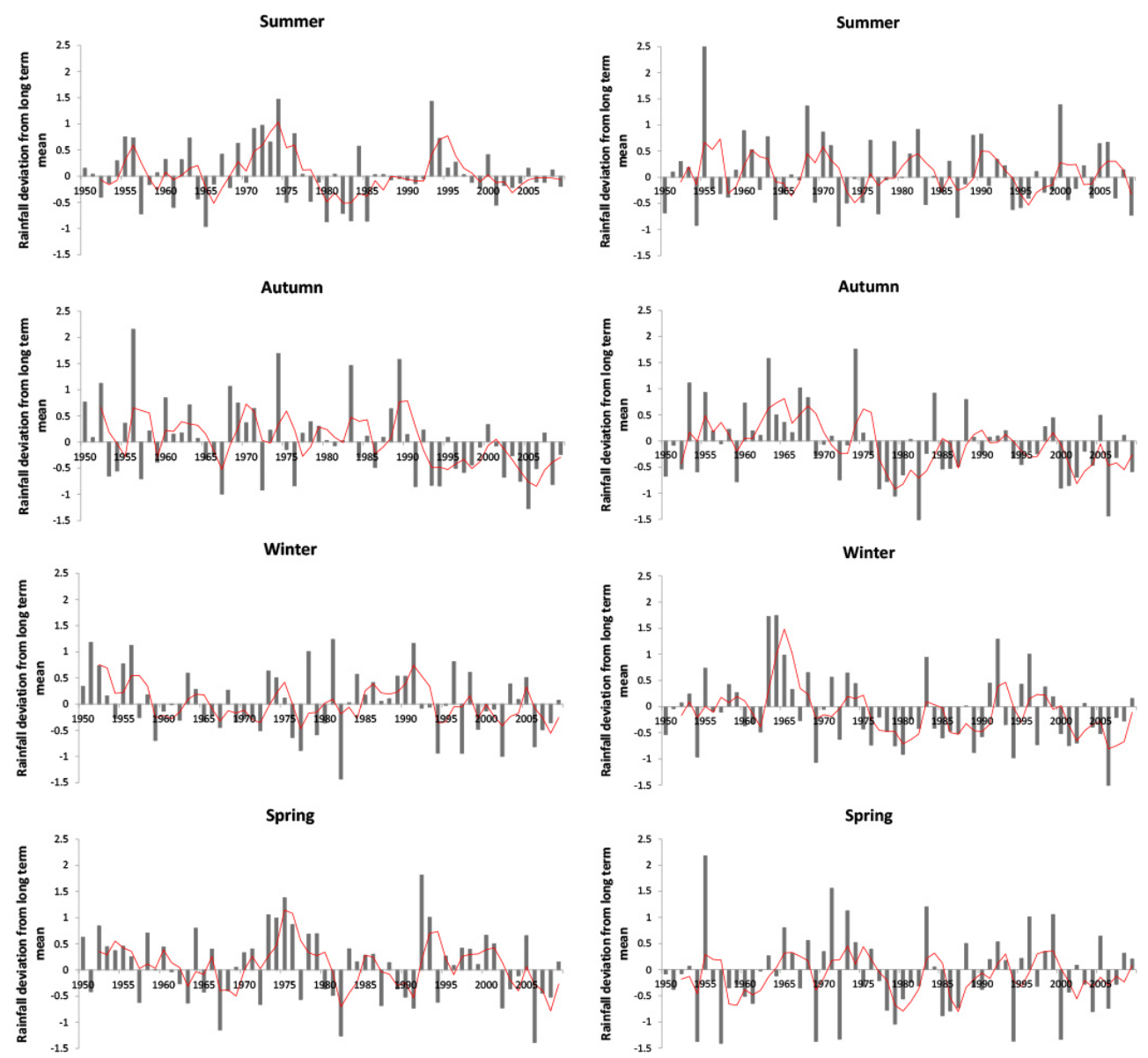

a)

b)

Figure 5. Rainfall deviation from the long-term mean (1900-2009) for (a) all SEA (left panel) and (b) all SWWA stations (right panel) combined. Note anomalies displayed from 1950 onwards.

of Frederickson et al. $(2005,2007)$ regarding a reduction in winter storm formation in the three decades from 1969.

\section{Comparison of rainfall anomalies in SEA and SWWA since the 1970s climate shift}

A comparative analysis between SEA and SWWA rainfall was carried out using the station-based rainfall data as described in Sect. 2.2. Normalised rainfall anomalies for the period 1900-2009 were combined and the time series plotted for all SEA stations and all SWWA stations for each season (Fig. 5).

Figure 5 shows that, following below-average summer rainfall and average autumn rainfall in the late 1970s in SEA, a series of eight consecutive back-to-back wetter than average winters occurred between 1984 and 1991 (actually 1983 is also slightly wetter than average, but is not considered as "wet" in this analysis), along with a series of wetter than average autumns in 1988, 1989 and 1990. Therefore, while the dominant mid-latitude trend had been towards dry since

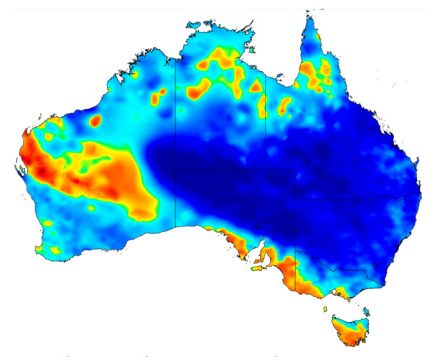

a) Autumn $(1988,1989,1990)$

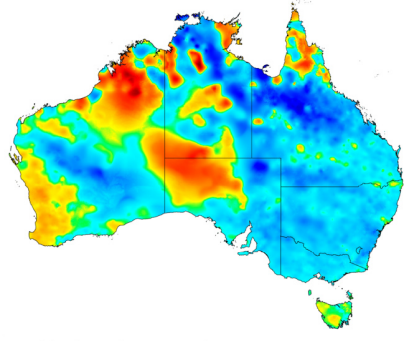

b) Winter (1984-1991)

Figure 6. Difference in (a) autumn and (b) winter rainfall during "wet seasons" compared to the long-term mean (1900-2009).

the mid-1970s, other factors acted to offset the trend for SEA during these wet autumn/winter seasons. Importantly, in terms of winter rainfall, the series of eight back-to-back wet events is unprecedented in the 100-year instrumental record. It can also be seen from Fig. 5 that the mid-1980s to early 

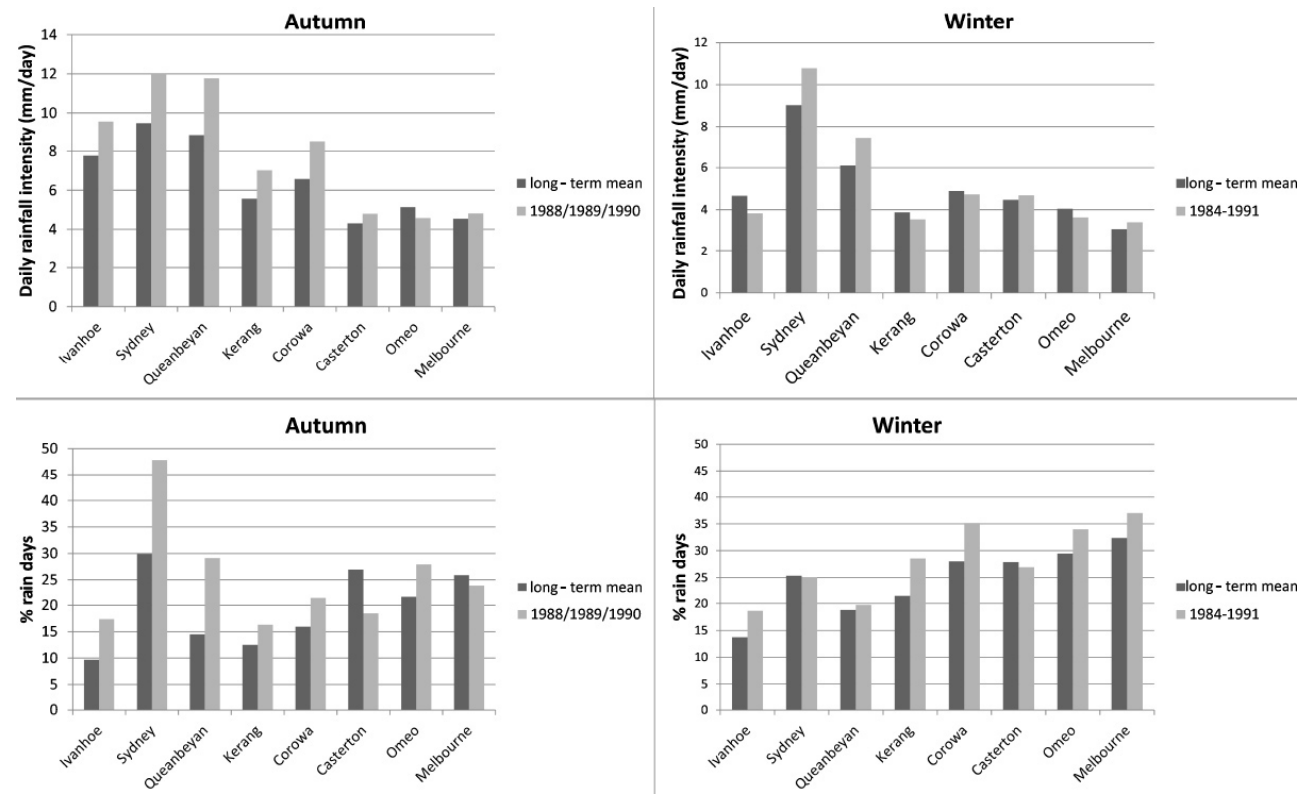

Figure 7. Daily rainfall intensity and percentage of rain days for the eight selected high-quality rainfall stations in SEA during wet years compared to long-term mean (1900-2009).

1990s autumn and winter rainfall relief did not occur simultaneously in SWWA; rather these seasons have consistently been dry since the mid-1970s for this region. The results presented here also indicate that, based on the station data used in our analysis, the cool season drying trend in SWWA occurred starting from the mid-1970s (rather than the late 1960s as reported by Hope et al., 2009).

The spatial nature of these wetter than average autumn and winter conditions is analysed in Fig. 6. In this figure "wet seasons" are defined as 1988-1990 for autumn and 19841991 for winter (based on the analysis presented above).

Figure 6a shows that the enhanced autumn rainfall during the period 1988-1990 occurred in a broad northwest to southeast band across the continent. Not all SEA regions experienced this elevated autumn rainfall; however, as shown in Fig. 6a, southern regions of South Australia, Victoria and Tasmania actually experienced a decrease in rainfall during this time. Figure $6 \mathrm{~b}$ shows that the elevated winter rainfall during the 1984-1991 period penetrated all of SEA (note SWWA did not receive this winter relief and hence the overall drying trend initiated in the mid-1970s continued without interruption in this region).

Thus far the rainfall has been analysed in terms of seasonal totals, however, changes in daily rainfall statistics (i.e. changes to the frequency, intensity, duration and/or sequencing of rainfall events) have important hydrological implications, as this will influence soil moisture and, in turn, the runoff generated. Therefore, daily characteristics of the seasonal rainfall during the elevated rainfall seasons identified above were analysed using the station-based daily rainfall data (refer to Sect. 2.2 and Fig. 1b). Figure 7 shows the daily rainfall intensity and percentage of rain days (defined as any day with rainfall greater than $1 \mathrm{~mm}$ ) for the eight daily rain stations during autumn (1988/1989/1990) and winter (19841991) compared to the long-term mean.

As shown in Fig. 7, the autumns of 1988-1990 were associated with both an increase in rainfall intensity and number of rain days for those stations located in the region where seasonal rainfall totals were shown to be elevated in Fig. 6 . The stations in the region where autumn rainfall decreases were experienced (Casterton and Melbourne) either show no change, or a decrease in rainfall intensity and/or rain days during autumn. Overall, there is no evidence of increased rainfall intensity during the winters of 1984-1991 (with the exception of Queanbeyan and Sydney). The elevation in winter rainfall during this period is thus primarily a result of an increase in the number of rain days (i.e. the increase in rainfall appears to be due to the fact that it rained more often rather than due to an increase in daily intensity).

\section{Synoptic processes driving increases in autumn and winter rainfall during the mid-1980s to the early 1990s in SEA}

\subsection{Identification of synoptic types using self-organising mapping}

Given that the majority of enhanced autumn/winter rainfall is due to increased rain days (with some evidence of elevated rainfall intensity for autumn), persistent climate systems are most likely responsible for the elevated rainfall occurrence. Therefore, we have used a process to identify daily 


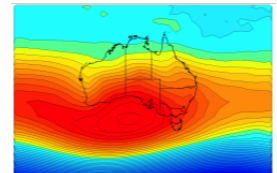

$1 \mathrm{~A}$

$2 \mathrm{~A}$

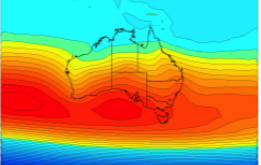

$3 \mathrm{~A}$

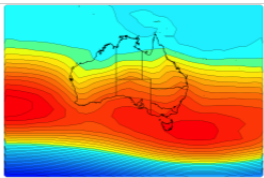

$4 \mathrm{~A}$

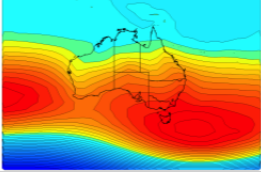

$5 \mathrm{~A}$

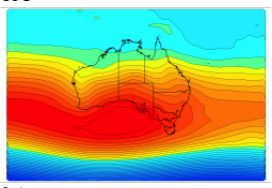

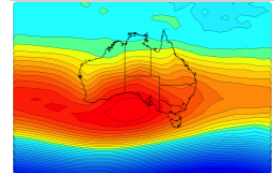

1B

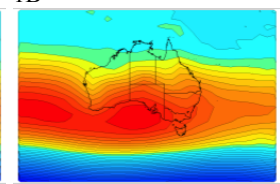

$2 \mathrm{~B}$

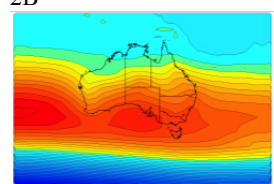

3B

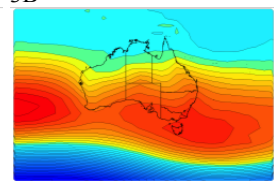

$4 B$

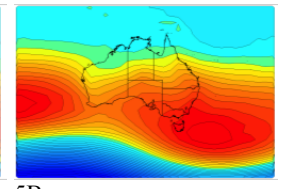

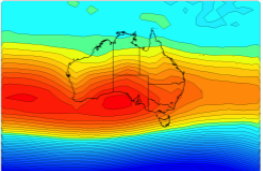

1C

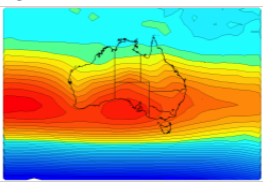

$2 \mathrm{C}$

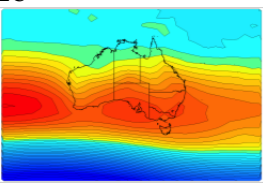

$3 \mathrm{C}$

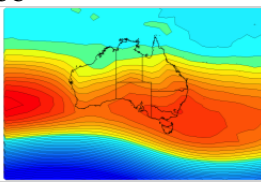

$4 \mathrm{C}$

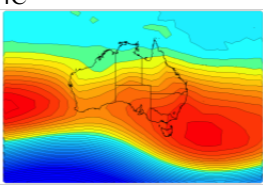

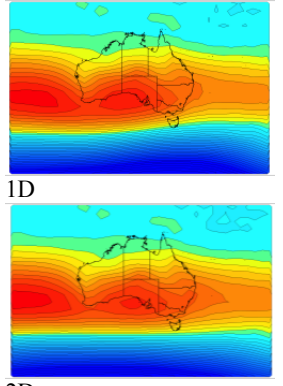

2D

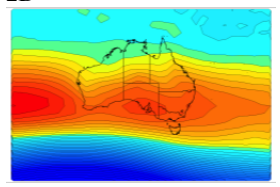

3D

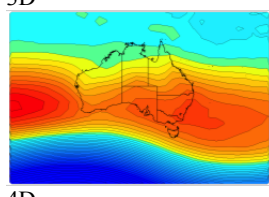

$4 \mathrm{D}$

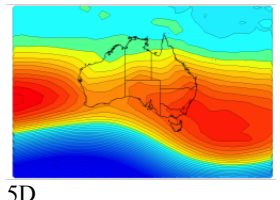

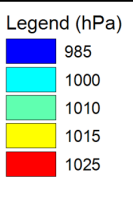

Figure 8. The 20 autumn synoptic types identified using SOM based on data from 1948-2009.

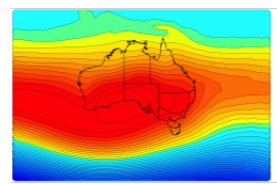

$1 \mathrm{~A}$

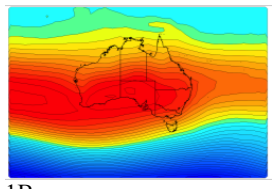

1B

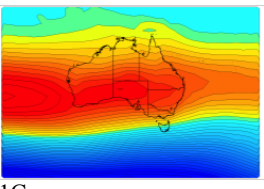

1C
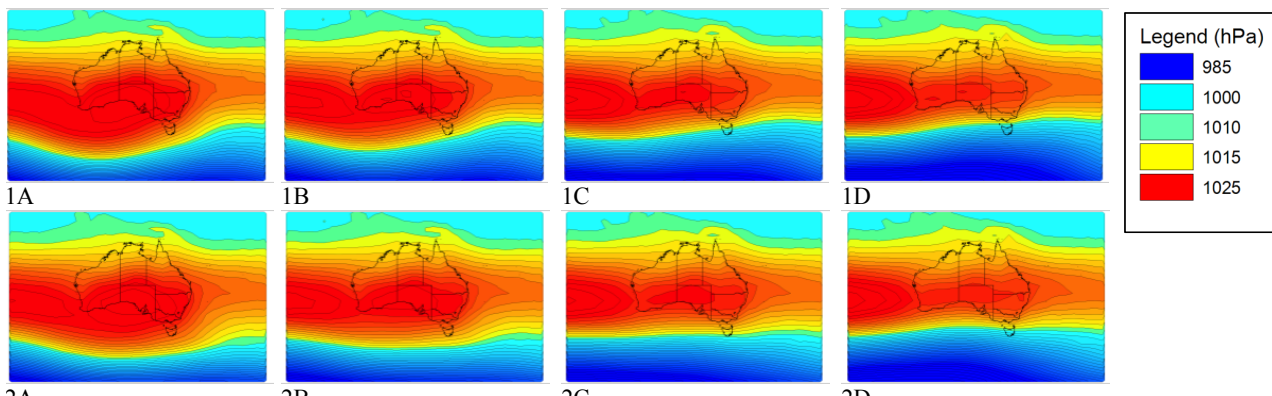

$2 \mathrm{~A}$

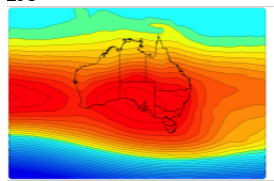

$3 \mathrm{~A}$

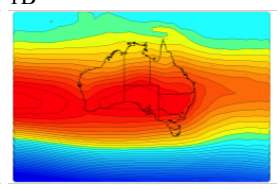

2B

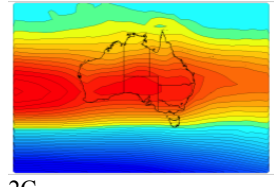

$2 \mathrm{C}$

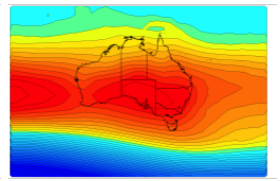

3B

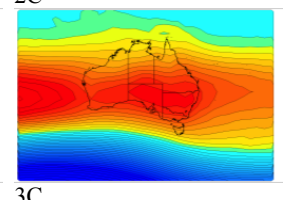

$3 \mathrm{C}$

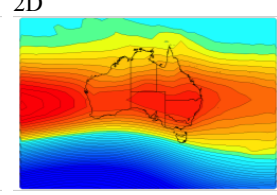

3D

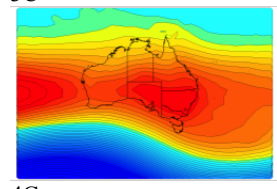

$4 \mathrm{C}$

$4 \mathrm{~A}$
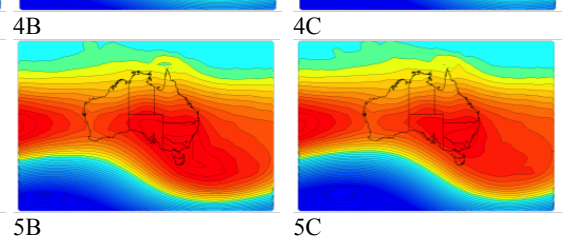

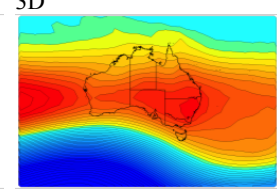

4D

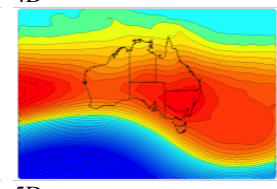

5

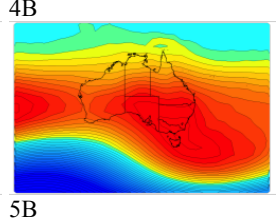

$5 \mathrm{D}$

Figure 9. The 20 winter synoptic types identified using SOM based on data from 1948-2009. 


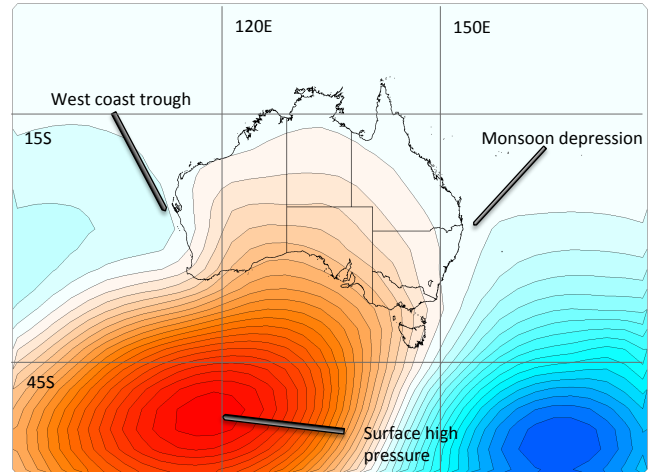

a)

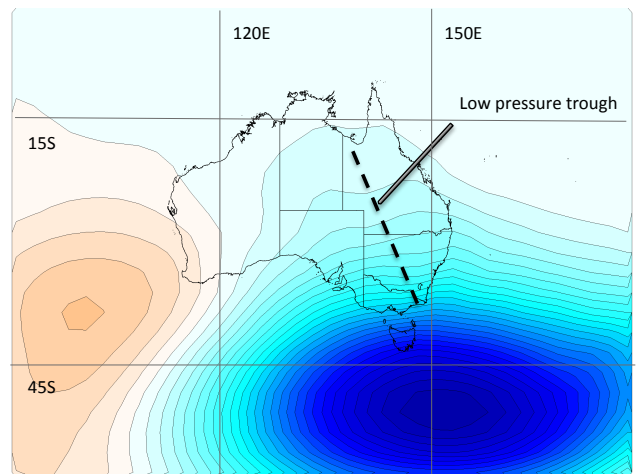

b)

Figure 10. (a) Synoptic type 1A expressed as an anomaly from the autumn mean. (b) Synoptic type 1D expressed as an anomaly from the winter mean. Note blue (red) indicates lower (higher) than average pressure.

synoptic systems that occurred during the period of elevated autumn/winter rainfall which can then be compared to the long-term climatology. The method by which the synoptic systems have been identified is known as a self-organising map (SOM). An SOM is a non-linear neural network classification technique developed to recognise relevant structures in complex, high-dimensional data via an unsupervised learning and self-adaptation process (Cavazos et al., 2002). SOMs have been described as less complex, more robust and less subjective than more traditional techniques, including cluster analysis and principal component analysis, which are commonly used to identify synoptic patterns (Hewitson and Crane, 2002). SOMs are essentially a mapping of many vectors onto a two-dimensional array of representative nodes (in this case synoptic types) via an unsupervised learning algorithm. The SOM methodology has been shown to be successful in identifying key regional synoptic patterns that drive local climate in other regions of the world (e.g. Cavazos, 2000; Cavazos et al., 2002; Hewitson and Crane, 2002; Hope et al., 2006; Reusch et al., 2007; Verdon-Kidd and Kiem, 2009b). Importantly, the SOM methodology is less subjective than other forms of pattern recognition, and the non-linear approach lends itself to regions where local climate is constantly changing due to large-scale climate variability.

Daily global sea level pressure (SLP) data for the years 1948-2009 was used to develop the SOM (see discussion of the NCEP/NCAR Reanalysis data in Sect. 2.1). This data set has been widely used in similar studies (e.g. Cavazos, 2000; Cavazos et al., 2002; Hope et al., 2006) and is considered to be the best SLP data available for the study region and type of analysis (see Hope et al., 2006 for a detailed discussion). In order to study the regional-scale synoptic systems that are important for SEA, a subset of the global SLP data was extracted to carry out the SOM. This region was chosen so as to capture the synoptic patterns that influence autumn and winter rainfall in SEA. Two separate SOMs were generated - one for autumn (MAM) and another for winter (JJA). The location of the SLP field used in this analysis is $90-180^{\circ} \mathrm{E}$, $0-60^{\circ} \mathrm{S}$.

The size of the SOM array directly influences the range of synoptic patterns represented. A number of array sizes were trialled in order to determine the optimum number of synoptic patterns. It was determined that a $3 \times 4$ SOM (i.e. 12 types) was not large enough to adequately identify the subtle differences between types that are likely to be important in generating rainfall; however these subtleties were found to be captured by a $4 \times 5$ SOM (i.e. 20 types). Larger array sizes (e.g. a $5 \times 6 \mathrm{SOM}$ ) resulted in further refinement of the transitionary synoptic types (resulting in very discrete differences between types), yet did not alter the extreme types. In addition, there was no improvement in the mean error per sample (calculated as the average Euclidian distance between the input vector and the synoptic types it best matches) by increasing the size of the SOM array beyond 20 types. Given these findings, a $4 \times 5 \mathrm{SOM}$ was chosen for the synoptic typing performed in this study - this array size satisfactorily captures extreme types and a range of synoptic patterns with sufficient differences observed between types.

Twenty synoptic types (using a $4 \times 5$ grid) were generated using the daily SLP data, as shown in Fig. 8 (autumn) and Fig. 9 (winter). By virtue of the method, similar types are clustered together in the SOM, with the most dissimilar types located at the far corners of the SOM map.

A range of synoptic systems for both seasons were identified using the SOM methodology. In general, the top half of the SOM represents systems with a westerly flow (since winds move in the direction of high to low pressure), while the bottom half of the SOM represents easterly flow. Systems with a westerly flow are more likely to bring rain into eastern Australia (particularly west of the Great Dividing Range); however, coastal stations may benefit from easterly systems if they are laden with moist air (for example, a "black noreaster"). The westerly systems are more likely to deliver lower intensity, longer duration events, while the easterly 

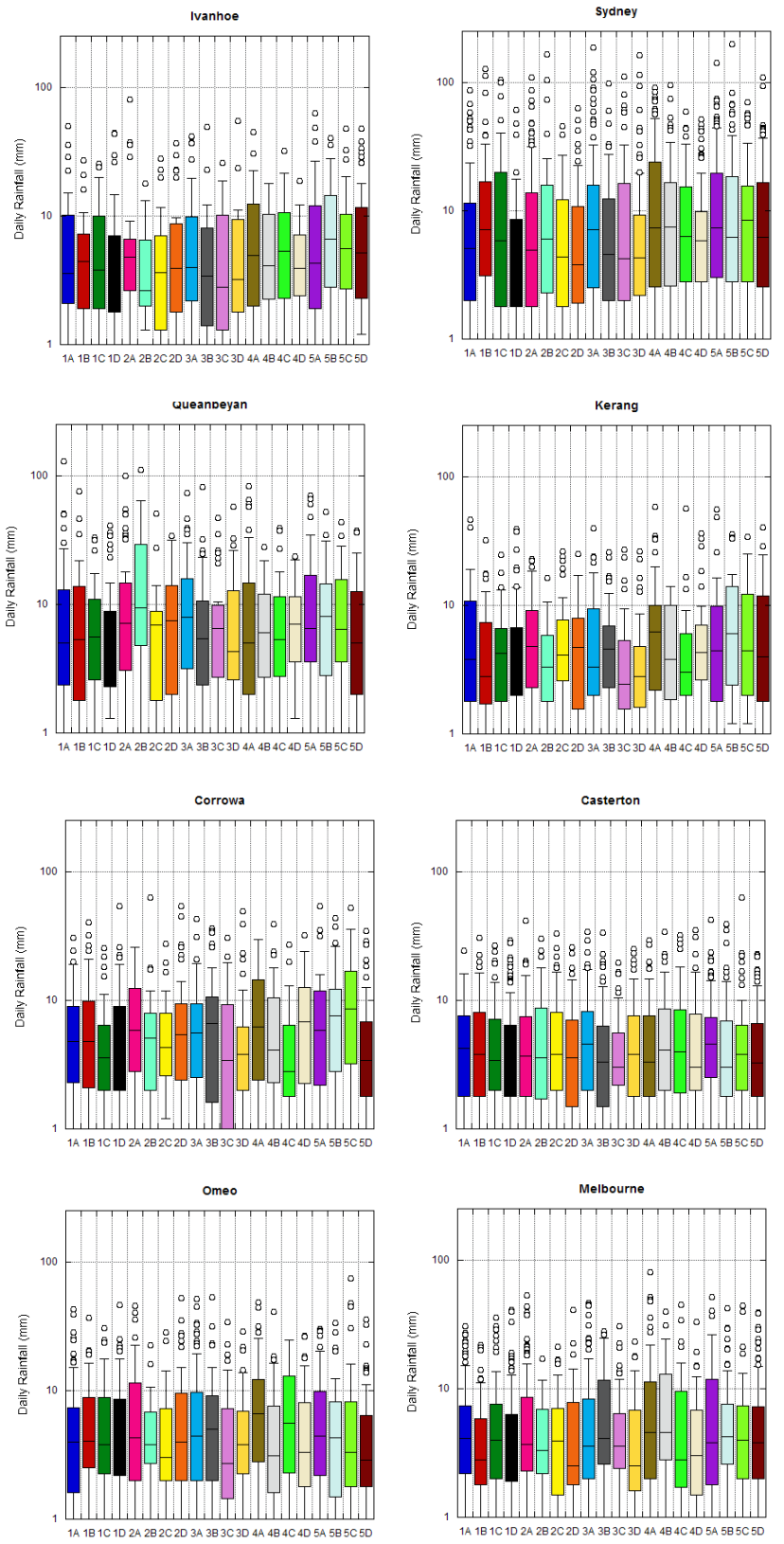

Figure 11. Daily rainfall distributions associated with each autumn synoptic type.

systems are more likely to deliver rainfall in shorter, more intense storm events (from cut-off lows, east coast lows, etc.). The types located along Row 3 of the SOM (Figs. 8 and 9) show a southward retraction of the Subtropical Ridge. This is likely to result in reduced rainfall across SEA (a more summer-like pattern) due to the surface high pressure being located over southern Australia (Sturman and Tapper, 2004).

Autumn synoptic types located in the top left-hand corner (1A, 1B, 2A) of Fig. 8 show a monsoon depression over eastern Australia, as seen by the strong "dip" in the isobars over eastern Australia (note also the low pressure trough over
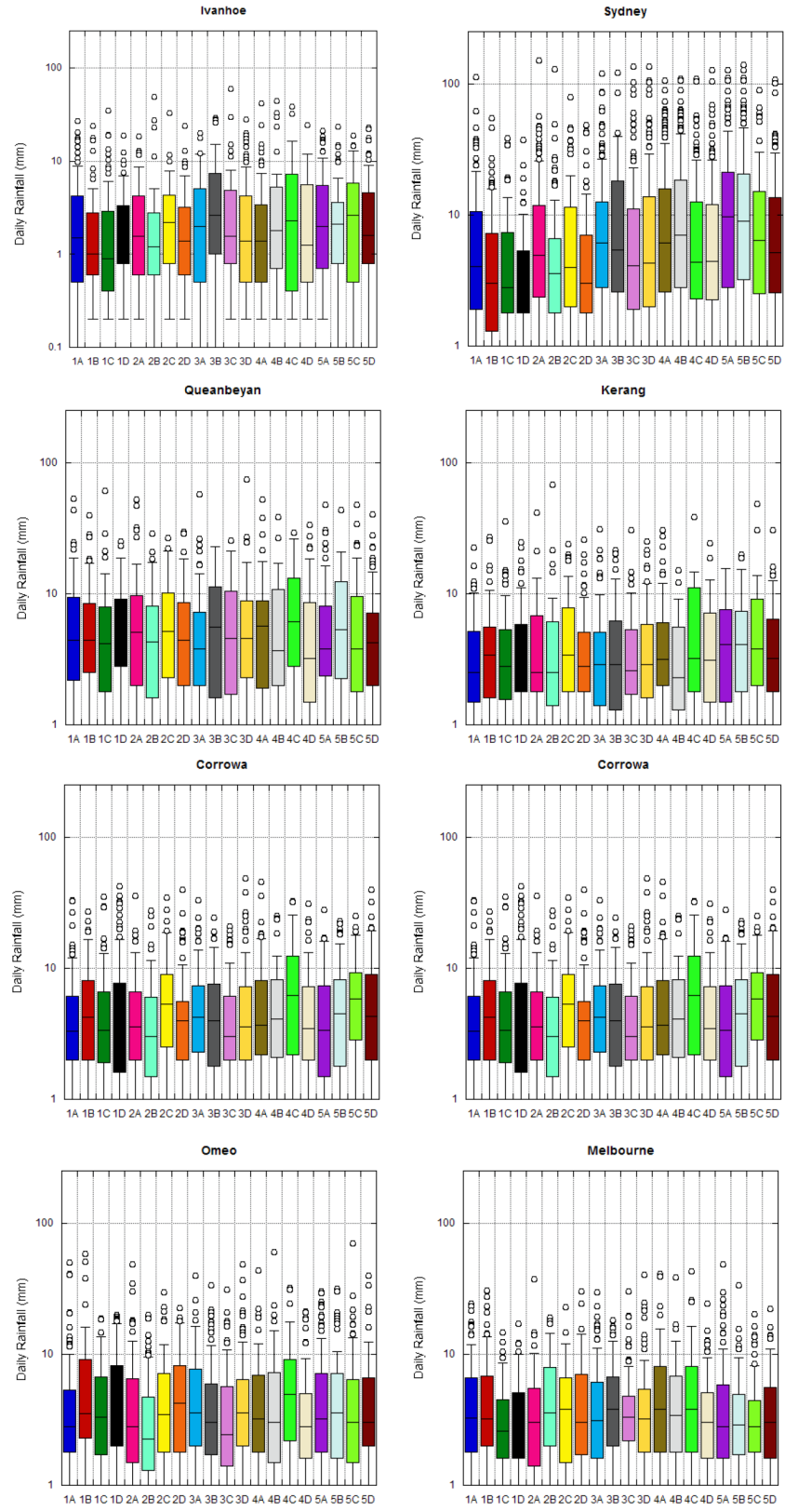

Figure 12. Daily rainfall distributions associated with each winter synoptic type.

western Australia, known as the "west coast trough" that occurs at this time of year and results in dry conditions for SWWA). To aid in interpretation of the SOM results, these features are highlighted in Fig. 10a, which displays synoptic type $1 \mathrm{~A}$ as a seasonal anomaly. Monsoon depressions often have their origin in the northwest of the continent and move southeast, bringing warm moist air that often results in prolonged rainfall (particularly west of the Great Dividing Range). This type of system was responsible for the breaking of the severe 1982/83 drought (Tapper and Hurry, 1996), and more recently was the primary weather system that resulted 


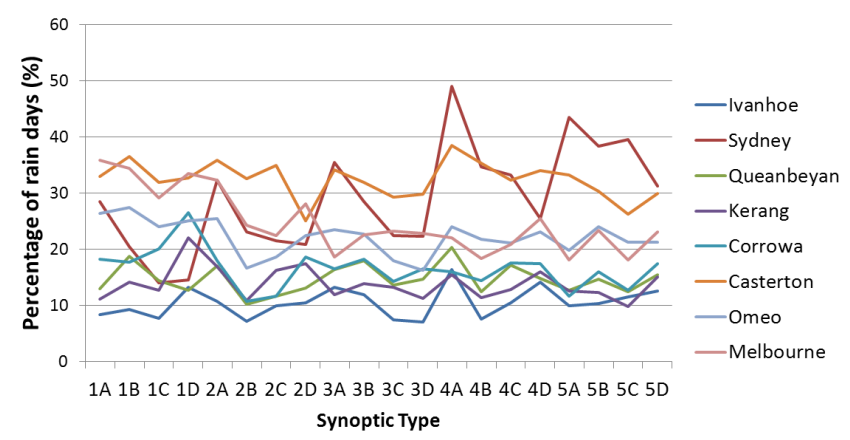

Figure 13. Percentage of rain days associated with each autumn synoptic type.

in elevated rainfalls in 2010/11. The strong surface high pressure system located to the south of Australia in the "Bight" (also highlighted in Fig. 10a) is likely to block the propagation of the rain-bearing systems into the southern regions, and can even lead to a "cold outbreak" in southern Victoria and South Australia (Tapper and Hurry, 1996). Occasionally, east coast lows can also form out of these monsoon depressions, resulting in heavy recorded rainfall for east coast stations.

Similar synoptic patterns to those observed in autumn were identified for winter. However, some key differences were observed. In particular, as shown in Fig. 9, winter types 1C, 1D and 2D display a low pressure trough stretching from the northwest through to the southeast of the continent (note this feature is also highlighted as a seasonal anomaly in Fig. 10b to aid interpretation). The low pressure trough represents conditions suitable for cloud band development, a system common in winter and spring and less common in autumn. The "northwest cloud bands", as they are known, often result in substantial rainfall across SEA in the winter and spring seasons. Similar to low pressure trough systems, the type of rainfall associated with northwest cloud bands tends to be of a lower intensity and longer duration than isolated low pressure systems (such as east coast lows, Tasman lows, etc.).

\subsection{Rainfall statistics associated with the 20 autumn and winter synoptic types}

The daily rainfall associated with each autumn and winter synoptic type is shown in Fig. 11 (autumn) and Fig. 12 (winter). Note that days with zero rain were removed in this analysis in order to demonstrate how much rain is associated with each type when that type results in rainfall. The percentage of rain days associated with each synoptic type is shown in Fig. 13 (autumn) and Fig. 14 (winter).

From Figs. 11 and 12 it is clear that daily rainfall distributions vary markedly for different synoptic types at the same site (and for the same synoptic type across the different sites). For example, the most intense rainfall in autumn is associ-

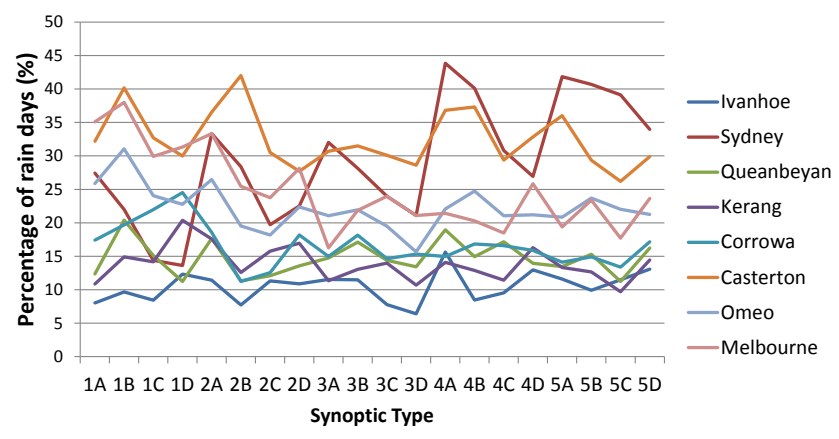

Figure 14. Percentage of rain days associated with each winter synoptic type.

ated with type 5B at Ivanhoe and Kerang, 4A at Sydney and Omeo, 2B at Queanbeyan, 5C at Corowa, 3A/4C at Casterton and $4 \mathrm{~B}$ at Melbourne. These types are clustered in the bottom left corner of the SOM in Fig. 8 (strong easterly flow).

There is also a clear trend in the number of rain days associated with each synoptic type, as demonstrated by Figs. 13 and 14. For those stations located in the northern part of the study region (e.g. Sydney and Ivanhoe) there is a general increase in rain days in both autumn and winter for those synoptic types located in the bottom half of the SOM, while for stations located in the south of the study region (e.g. Corowa, Casterton, Omeo and Melbourne) the opposite is true (i.e. a greater number rain days occur for synoptic types located in the top half of the SOM). This indicates that the more southern stations benefit most from westerly flow, while those located further north benefit from easterly systems. The four stations located in the south of the study region are within the "Victorian" region as defined by Timbal et al. (2010) which, according to the authors, is most strongly influenced by local mean sea level pressure in autumn and winter, with the Southern Annular Mode (i.e. westerly flow) also playing a significant role in winter. The stations in our study that are located further north correspond to the regions defined as "Central" and "Eastern" by Timbal et al. (2010) which, according to the authors, are most strongly influenced by the Pacific driver (i.e. ENSO) which affects easterly systems.

\subsection{Relative occurrence of synoptic types during the wetter than average autumns of 1988-1990 and winters of 1984-1991}

Next we investigate how frequently each synoptic type occurred during the wetter than average autumns (1988-1990) and winters (1984-1991) in order to determine which (if any) types were responsible for the elevated rainfall during these seasons. The relative percentage of each synoptic type occurring during the wetter than average autumns of 1988-1990 and winters of 1984-1991 are shown in Fig. 15 compared to the long-term climatology (based on the period 1948-2009). 

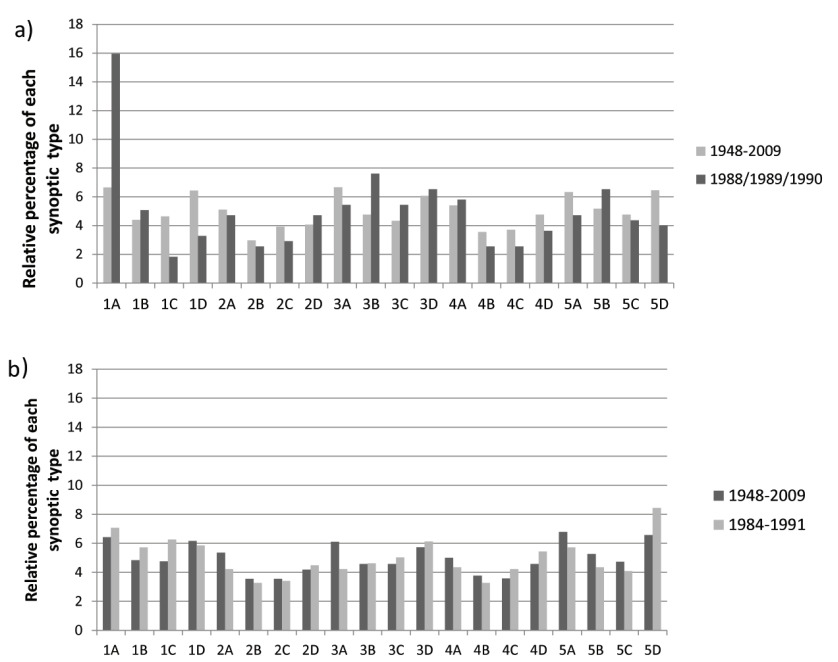

Figure 15. Relative percentage (frequency of occurrence) for each synoptic type during (a) autumn 1988-1990 and autumn 19482009, (b) winter 1984-1991 and winter 1948-2009.

Figure 15a shows a large increase in type 1A during the wet autumns of 1988-1990 (result statistically significant at $<10 \%$ ( $p$ value 0.07 ) using a Student's $t$ test), representing a monsoon depression over eastern Australia. As noted previously, this system often results in substantial rainfall across SEA (however, the presence of a west coast trough is associated with dry conditions in SWWA). There is also a general increase in synoptic types representing westerly flow (as opposed to easterly flow).

Based on Fig. 15b there appears to be two separate weather systems that were more common than usual during the wet winter period of 1984-1991. Increases in synoptic types located along the first row of the SOM indicate that, as for autumn, monsoon trough systems over the east coast were more frequent, along with cloud band development. These systems are also associated with strong westerly flow. In addition, an increase in types located in the bottom right corner of the SOM (representing systems with a very strong easterly flow) would have resulted in rainfall being generated from the Pacific in the form of cut-off lows, which are closed low pressure systems that have become completely displaced from the basic westerly current flowing across Australia's southern oceans (Tapper and Hurry, 1996). While these increases were not found to be statistically significant using a Student's $t$ test, a small increase in "wet" synoptic types may have a larger impact on the seasonal rainfall totals.

An assumption that has been made thus far is that the likelihood of rainfall for a given synoptic type is stationary and consistent in time. In order to analyse the validity of this assumption, the percentage change in the likelihood of rainfall occurrence (i.e. a day with rain $>1 \mathrm{~mm}$ ) for a given synoptic type during the wet autumns of 1988/1989/1990 compared to the long-term climatology was calculated (Table 1). Sim- ilarly, results for winter (1984-1991 compared to the longterm mean) are shown in Table 2. Note that a small deviation is not unexpected given the reduced sample size of daily synoptic types during the "wet" seasons compared to the longterm climatology.

Table 2 shows that the likelihood of rain for a given synoptic type during winter is fairly consistent for the time periods being analysed. However, in the autumns of 1988-1990 there does appear to be a trend towards more rain days for a given synoptic type (up to $50 \%$ more in some cases), as shown in Table 1. An initial investigation into climate variables other than sea level pressure has highlighted some interesting findings that may help explain why some stations received so much rain during this period. For example, Fig. 16 shows precipitable water anomalies, SST anomalies, scalar wind speed and outgoing longwave radiation, during the wet autumns of 1988-1990.

Figure 16a shows that a pool of precipitable water was centred over southern Queensland, New South Wales and northern Victoria during the autumns of 1988-1990, which is likely to have increased the chance of rain for a given synoptic system. Another reason for an increased chance of rain in autumn (for Sydney in particular) may be due to warmer than average SSTs (shown in Fig. 16b) off the west coast of Australia feeding moisture to the westerly winds. Thirdly, the outgoing longwave radiation (Fig. 16c) is particularly low along eastern Queensland and New South Wales during this time. Low longwave radiation is typically associated with increased storm activity and subsequent rainfall. Therefore, both the moisture source and the atmospheric processes that actually deliver the rainfall were available during this time.

While some preliminary insights have been gained, the reason why Sydney received so much rainfall during the autumns of 1988-1990 requires further investigation. Indeed it is likely that local climate phenomena not studied here may have played a role (i.e. phenomena that are too small to be captured based on the synoptic types using NCEP/NCAR grid resolution).

\section{Role of large-scale climate phenomena in driving en- hanced autumn and winter rainfall during the mid- 1980 s to the early 1990s in SEA}

Numerous studies have demonstrated that the four most influential climate modes on SEA's climate are

- El Niño-Southern Oscillation (ENSO; Chiew et al., 1998; Kiem and Franks, 2001; Verdon et al., 2004) - ENSO is represented by the Oceanic Niño Index (ONI) from the United States National Oceanic and Atmospheric Administration (NOAA) Climate Prediction Centre (CPC) (www.cpc.ncep.noaa.gov). The ONI is a 3-month running mean of ERSST.v3b SST anomalies in the Niño 3.4 region, centred on 30-year base periods updated every 5 years. For historical purposes, cold (La 
Table 1. Percentage change in the likelihood of a rain day (greater than $1 \mathrm{~mm}$ ) for a given synoptic type during the autumns of 1988-1990 compared to the 1948-2009 period (substantial deviations from the long-term mean $(>20 \%$ or $<-20 \%)$ are highlighted in italic).

\begin{tabular}{crrrrrrrr}
\hline Type & Ivanhoe & Sydney & Queanbeyan & Kerang & Corowa & Casterton & Omeo & Melbourne \\
\hline 1A & 5 & 10 & 8 & 3 & 7 & -10 & 3 & -6 \\
1B & 19 & 8 & 10 & 0 & -11 & -8 & 1 & 8 \\
1C & 52 & 46 & 46 & 7 & 40 & 8 & 16 & -9 \\
1D & -2 & 30 & -2 & 0 & -4 & -10 & -3 & -11 \\
2A & 5 & -2 & 14 & -2 & -10 & -20 & -2 & -2 \\
2B & 7 & 34 & 18 & -11 & -11 & -4 & -17 & -24 \\
2C & 15 & -9 & 13 & 21 & 1 & -10 & 6 & 3 \\
2D & -3 & 18 & -5 & -2 & 4 & -17 & 1 & 3 \\
3A & -6 & 25 & -3 & 1 & -10 & -27 & -3 & 1 \\
3B & -7 & 14 & 6 & -4 & -4 & -13 & -4 & -8 \\
3C & 26 & 11 & 6 & 13 & 19 & -23 & 22 & 17 \\
3D & 10 & 22 & 8 & 11 & 11 & -13 & 12 & 11 \\
4A & -10 & 38 & 11 & -9 & -3 & -7 & -5 & -16 \\
4B & 50 & 37 & 30 & 3 & 43 & -21 & 21 & -4 \\
4C & -10 & 10 & -17 & -13 & -3 & -4 & -7 & -7 \\
4D & 6 & 25 & 5 & 4 & 3 & 6 & 17 & -5 \\
5A & 12 & 21 & 23 & 2 & 3 & -12 & 16 & 3 \\
5B & 1 & 17 & -3 & 4 & 1 & -30 & -2 & -18 \\
5C & 22 & 2 & 29 & 15 & 37 & -10 & 20 & -1 \\
5D & 6 & 41 & 3 & 12 & 10 & -30 & 24 & 22 \\
\hline
\end{tabular}

Table 2. Percentage change in the likelihood of a rain day (greater than $1 \mathrm{~mm}$ ) for a given synoptic type during winter 1984-1991 compared to the 1948-2009 period (substantial deviations from the long-term mean (>20\%) are highlighted in italic).

\begin{tabular}{crrrrrrrr}
\hline Type & Ivanhoe & Sydney & Queanbeyan & Kerang & Corowa & Casterton & Omeo & Melbourne \\
\hline 1A & -1 & -2 & 1 & -3 & 8 & -10 & 2 & 1 \\
1B & 5 & 7 & -2 & 5 & 5 & -8 & 2 & 7 \\
1C & 0 & 8 & -11 & -1 & -7 & -8 & -3 & 9 \\
1D & 4 & -3 & -3 & 0 & 0 & 2 & -5 & -5 \\
2A & 1 & -6 & -10 & 6 & 2 & -11 & -22 & 6 \\
2B & -4 & -4 & -9 & -4 & -1 & -13 & 1 & 4 \\
2C & 2 & 13 & 12 & -2 & 2 & -14 & 5 & 12 \\
2D & 1 & 3 & 4 & 12 & 14 & 6 & 21 & -2 \\
3A & 11 & 10 & -1 & 9 & 15 & -16 & 4 & -4 \\
3B & 8 & -5 & 3 & 13 & 4 & -24 & 13 & 11 \\
3C & 11 & 4 & -4 & 12 & 11 & 0 & 11 & 5 \\
3D & 0 & -10 & 0 & 11 & 10 & 1 & 2 & 12 \\
4A & -2 & 3 & -2 & 3 & -1 & 0 & 2 & 12 \\
4B & 5 & 4 & -10 & -3 & 3 & -6 & -2 & 3 \\
4C & 8 & -5 & -7 & 10 & 9 & 7 & -1 & 6 \\
4D & 16 & -2 & 4 & 19 & 19 & -12 & 18 & 18 \\
5A & 4 & 3 & 0 & 4 & -1 & 2 & 3 & 1 \\
5B & 9 & -3 & 0 & -6 & 5 & 0 & 0 & 1 \\
5C & 4 & 12 & 5 & -3 & 6 & -5 & 0 & -1 \\
5D & 4 & 1 & 1 & 7 & 8 & -12 & 5 & 5 \\
\hline
\end{tabular}




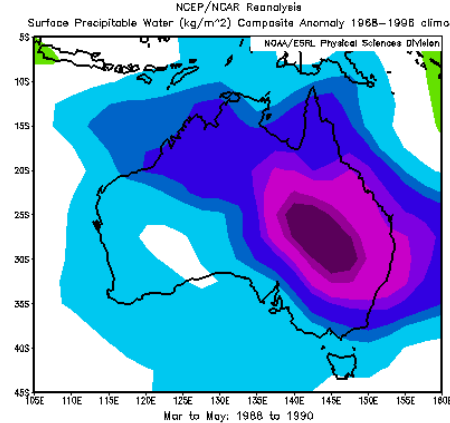

a)

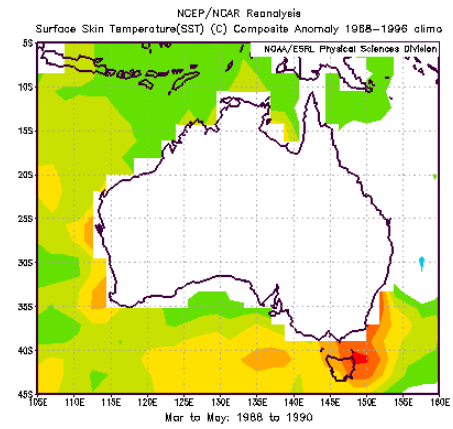

b)

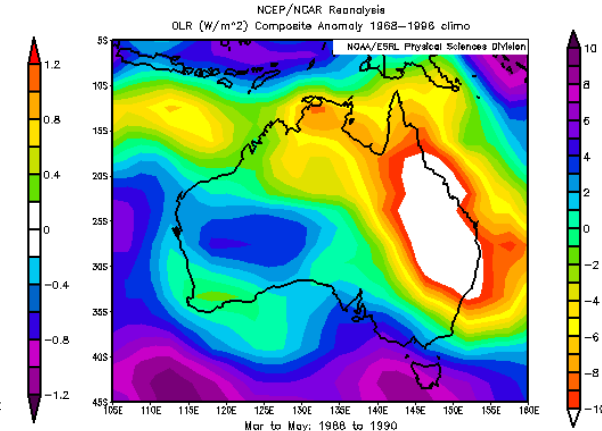

c)

Figure 16. (a) Precipitable water anomalies, (b) SST anomalies, (c) outgoing longwave radiation, during the autumns of 1988-1990.

Niña) and warm (El Niño) episodes are defined when the threshold $\left( \pm 0.5^{\circ}\right)$ is met for a minimum of 5 consecutive over-lapping seasons.

- Interdecadal Pacific Oscillation (IPO; Power et al., 1999; Kiem et al., 2003; Verdon et al., 2004; Power and Colman, 2006) - Both the raw and the smoothed time series of Power et al. (1999) are used in this study in order to identify epochs of positive and negative IPO.

- Indian Ocean Dipole (IOD; Saji et al., 1999; Ashok et al., 2003; Verdon and Franks, 2005) - SST anomalies to the northwest of Australia are used here rather than the IOD, as previous studies have shown that warming to the northwest of Australia (i.e. the eastern pole of the IOD) is the most important for cloud band development and is strongly related to above-average rainfall in SEA (e.g. Verdon and Franks, 2005), while the need for an anomaly further west has not been demonstrated. In fact, the poles of the IOD are not negatively correlated as one would expect (Dommenget and Latif, 2001; Gallant et al., 2012) and intermittent decoupling of the east and west pole of the IOD can lead to false classification of events.

- Southern Annular Mode (SAM; Thompson and Wallace, 2000; Thompson et al., 2000; Ho et al., 2012) The positive phase of SAM has been associated with reduced winter rainfall in SEA (e.g. Risbey et al., 2009) and also reduced autumn SEA rainfall via a reduction in frontal systems (e.g. Verdon-Kidd and Kiem, 2009b. Nicholls, 2009). In this study the NOAA CPC version of the AAO is used when it exists (i.e. from 1979 onwards) and the Thompson and Wallace (2000) AAO data is used prior to that (1948 to 1978). Overlapping periods (1979 to 2002) of the two versions of the AAO were compared and the difference found to be negligible $\left(R^{2}=0.95, N=288\right)$.

It is well known that the 1970s change in climate observed in the Southern Hemisphere (and parts of the Northern Hemi- sphere) corresponds to changes in both ENSO and IPO (e.g. Mantua et al., 1997; Power et al., 1999; Kiem and Franks, 2004; Verdon and Franks, 2006). Changes in Indian Ocean SSTs also occurred during this time (Verdon and Franks, 2005; Samuel et al., 2006). It has also been established that these large-scale climate modes modulate the frequency and timing of synoptic systems in Australia, at least at a monthly timescale (Verdon-Kidd and Kiem, 2009b). The question remains, however, whether these modes either collectively or individually can explain the increase in rainfall observed during autumn and winter of the late 1980s/early 1990s. Table 3 shows the state of each of the large-scale climate drivers during this wetter than average autumn and winter period. Note that while typically an ENSO event does not establish itself until after autumn (and therefore is unlikely to be a driver of autumn rainfall), the La Niña of 1988 was particularly long lasting and extended through the following autumn and winter of 1989.

Based on the analysis presented in Table 3 it may appear that SSTs to the northwest of Australia were primarily responsible for the elevated rainfall; however, it must be noted that in fact this region has been warmer than average during the entire period from the mid-1970s (including during the recent drought where autumn and winter rainfalls have been lower than average). What is clear from the analysis presented in Table 3 is that, for every wet season identified (except winter 1987) at least one of the four large-scale climate drivers was in a "wet phase". This indicates that, while a single climate mode can sometimes dominate, it is more often the interaction between drivers that is most important (Kiem and Verdon-Kidd, 2010). It also appears that the SAM plays an important role in the autumn rainfall relief (in that SAM is not positive during any of the wet autumns) but that a negative SAM on its own is not usually enough to ensure wetter than average conditions. This possibly explains why previous studies which analyse correlation relationships between SEA rainfall and SAM on its own conclude that SAM has minimal influence in autumn (e.g. Cai and Cowan, 2008a, b; Risbey et al., 2009). Based on the findings presented here 
Table 3. State of large-scale drivers during "wet seasons".

\begin{tabular}{clllll}
\hline Autumn & ENSO & IPO (smooth) & IPO (raw/annual) & $\begin{array}{l}\text { Northwest } \\
\text { of Australia SSTs }\end{array}$ & SAM \\
\hline 1988 & Neutral & Positive & Positive & Warm SSTs & Negative \\
1989 & La Niña & Positive & Negative & Warm SSTs & Neutral \\
1990 & El Niño & Positive & Negative & Warm SSTs & Negative \\
\hline Winter & & & & & \\
\hline 1984 & Neutral & Positive & Negative & Neutral & Negative \\
1985 & Neutral & Positive & Negative & Warm SSTs & Positive \\
1986 & El Niño & Positive & Positive & Warm SSTs & Positive \\
1987 & El Niño & Positive & Positive & Neutral & Neutral \\
1988 & La Niña & Positive & Negative & Warm SSTs & Negative \\
1989 & Neutral & Positive & Negative & Warm SSTs & Neutral \\
1990 & El Niño & Positive & Negative & Warm SSTs & Neutral \\
1991 & El Niño & Positive & Positive & Neutral & Negative \\
\hline * Power et al. (1999a) applied a spectral filter with a 13-year cut-off to the raw IPO (i.e. annual value) to generate a \\
smoothed (or slowly varying) IPO time series. & & &
\end{tabular}

(also Kiem and Verdon-Kidd, 2010), we suggest that this is unlikely to be true, and that SAM does indeed play an important role in modulating autumn/winter rainfall in SEA; however, this modulating effect is dependent on the phase of the Pacific Ocean and Indian Ocean drivers (see Kiem and Verdon-Kidd, 2010 for more details).

Of particular interest is the winter of 1991, which was extremely wet and the only climate mode in a wet phase at the time was the SAM, demonstrating that SAM does indeed have an influence; however, this result also indicates that correlation studies of SAM and rainfall may be skewed by this one very wet winter and negative SAM. Also of interest is the winter of 1987 where ENSO was in a dry phase, and the Indian and Southern Modes were neutral (indicating that rainfall would be expected to be average to below average). The rainfall for this season was only slightly elevated (whereas the other seven winters were substantially above average). However, this result points to the fact that it is also possible that other climate drivers may have played a role that has not been considered here - for example upper atmosphere phenomena or small-scale synoptic systems.

\section{Implications for water resource management in SEA}

There is evidence that changes in the dominant Southern Hemisphere climate drivers experienced during the mid1970 s created a shift to drier than average conditions across most of the mid-latitude belt. However, a series of wetter than average winters in SEA during the 1984-1991 period (and three wet autumns), due to weather systems originating primarily from the tropical Indian Ocean (i.e. northwest cloud bands and monsoon depressions) prevented, delayed or interrupted this change in climate in SEA.
What would have happened to water resources and supplies in the region in the absence of these wet winters and autumns? Given the experience of SWWA and the findings presented here, it is suggested that this should be considered as a possible "scenario" in terms of water management planning, and indeed water corporations in Victoria are using an immediate return to the dry conditions of the Big Dry as a possible future scenario alongside climate change projections (DSE, 2011).

To demonstrate the importance of considering such a scenario, a simple analysis of the effects on soil moisture and streamflow has been carried out. To achieve this, the observed rainfall sequences were altered such that the elevated rainfall totals actually experienced during the winters of 1984-1991 were replaced by the long-term mean winter rainfall. Similarly, the autumns of 1988, 1989 and 1990 were replaced with the long-term autumn mean rainfall. This perturbed synthetic rainfall sequence was then used to calculate the monthly value of the Palmer Drought Severity Index (PDSI, Palmer, 1965), a physically based index of meteorological drought that takes into account precipitation, evapotranspiration and soil moisture conditions, all of which are determinants of agricultural drought (Alley, 1984). Droughts are classified based on PDSI values between -10 (extreme drought) and +10 (extremely wet). The calculation of the PDSI also requires maximum temperature data (which was sourced from the BoM for the locations at the rainfall gauges). Sheffield et al. (2012) highlighted significant issues with the PDSI in terms of overestimation of drought (albeit on a global scale) given that the index uses a simplified model of potential evaporation that responds only to changes in temperature (see Mishra and Singh, 2010 for a comprehensive review of drought indices). In the absence of local meteorological data required to calculate potential evaporation using 

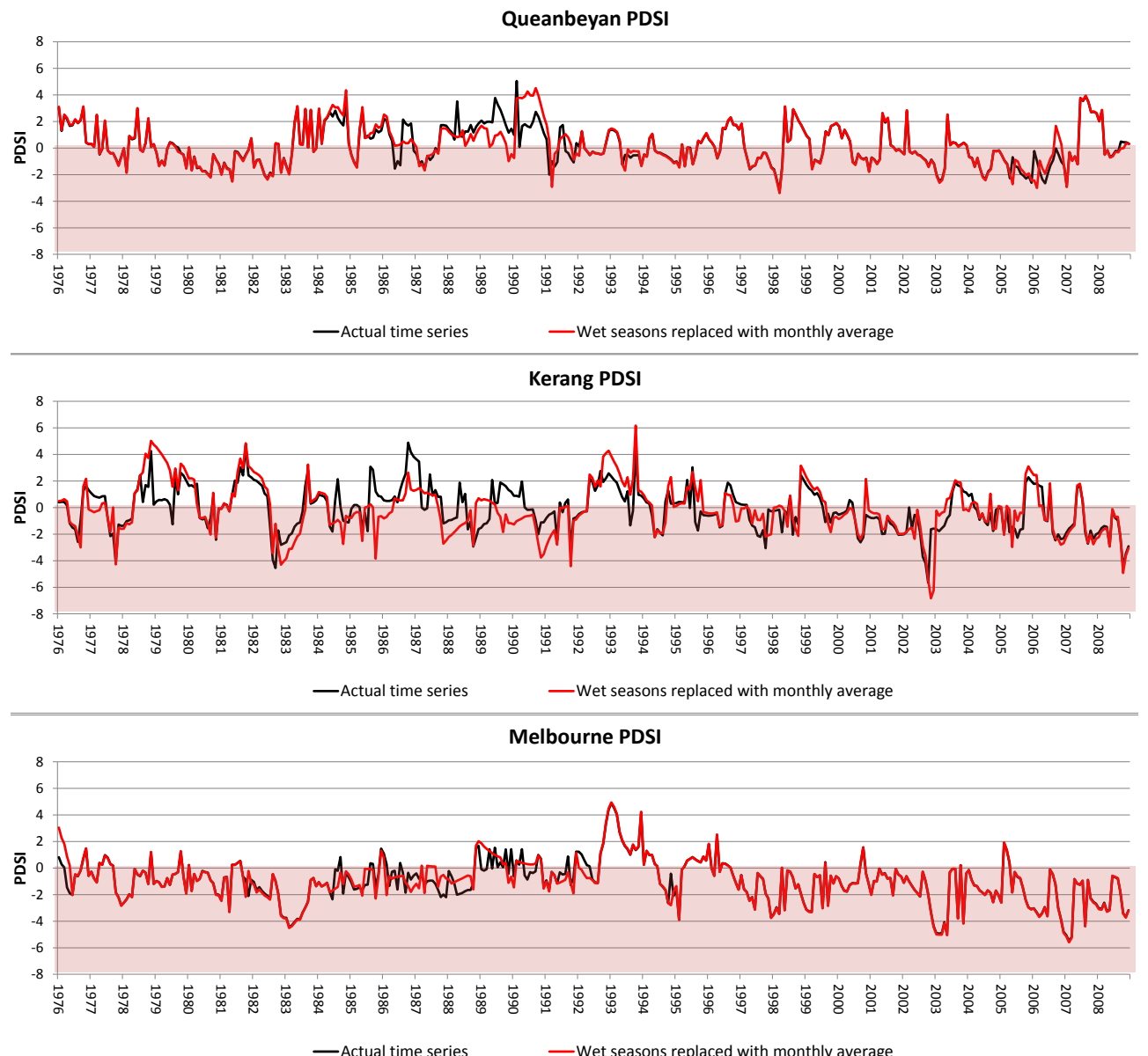

Figure 17. Monthly time series of PDSI from 1976 to 2009 at Queanbeyan, Kerang and Melbourne (red shading shows PDSI values that indicate dry conditions).

the Penman-Monteith method (a physically based estimate of potential evaporation), a second measure of drought, the Standardized Precipitation Index (SPI, McKee et al., 1993) was calculated to compare with the PDSI results. The SPI is a purely statistical measure of meteorological drought that requires only precipitation as input, where negative values of the SPI indicate dry conditions (values $<-2$ represent extreme drought). It is acknowledged that all indices used to measure drought are only proxies (with associated pros and cons); however, the analysis presented here is simply to demonstrate the potential changes in drought conditions that could have been experienced had the elevated rainfalls in autumn/winter of the later 1980s and early 1990s not occurred.

Figure 17 shows the time series of the PDSI for Queanbeyan, Kerang and Melbourne in SEA (see Figure $1 b$ for locations) calculated using the instrumental record and then again using the "altered" rainfall sequence. Figure 18 shows the SPI time series for the same locations. Note drought indices are shown from 1976 only; however, the long-term indices were calculated over the entire instrumental record.
Figures 17 and 18 confirm that drought conditions (varying degrees of severity) associated with the Big Dry occurred between the mid-1990s through to 2009 at Kerang and Melbourne, while the drought appears to be less severe for Canberra (based on the PDSI and SPI). Based on both the PDSI and SPI time series for Melbourne (the most southerly station analysed here), the period from 1976 through to the late 1980s was also consistently dry, similar to SWWA.

It can be seen from Figs. 17 and 18 that replacing the wetter than average autumns and winters of the 1980s and early 1990s with average rainfall has an impact on the drought index time series at all stations for both indices to varying degrees. The largest impact on drought conditions was obtained at Kerang (the most inland station analysed here), particularly for the PDSI. It can be seen from Fig. 17 that, in the absence of wetter than average winters (1984-1991) and autumns (1988-1990), the return to "wet" soil moisture conditions (i.e. PDSI $>0.5$ ) experienced between $\sim 1984-1991$ at Kerang would not have occurred. Based on the recorded data (actual time series) dry (PDSI $<-0.5$ ) conditions prevailed $33 \%$ of the time between 1984-1991 compared to $55 \%$ of 

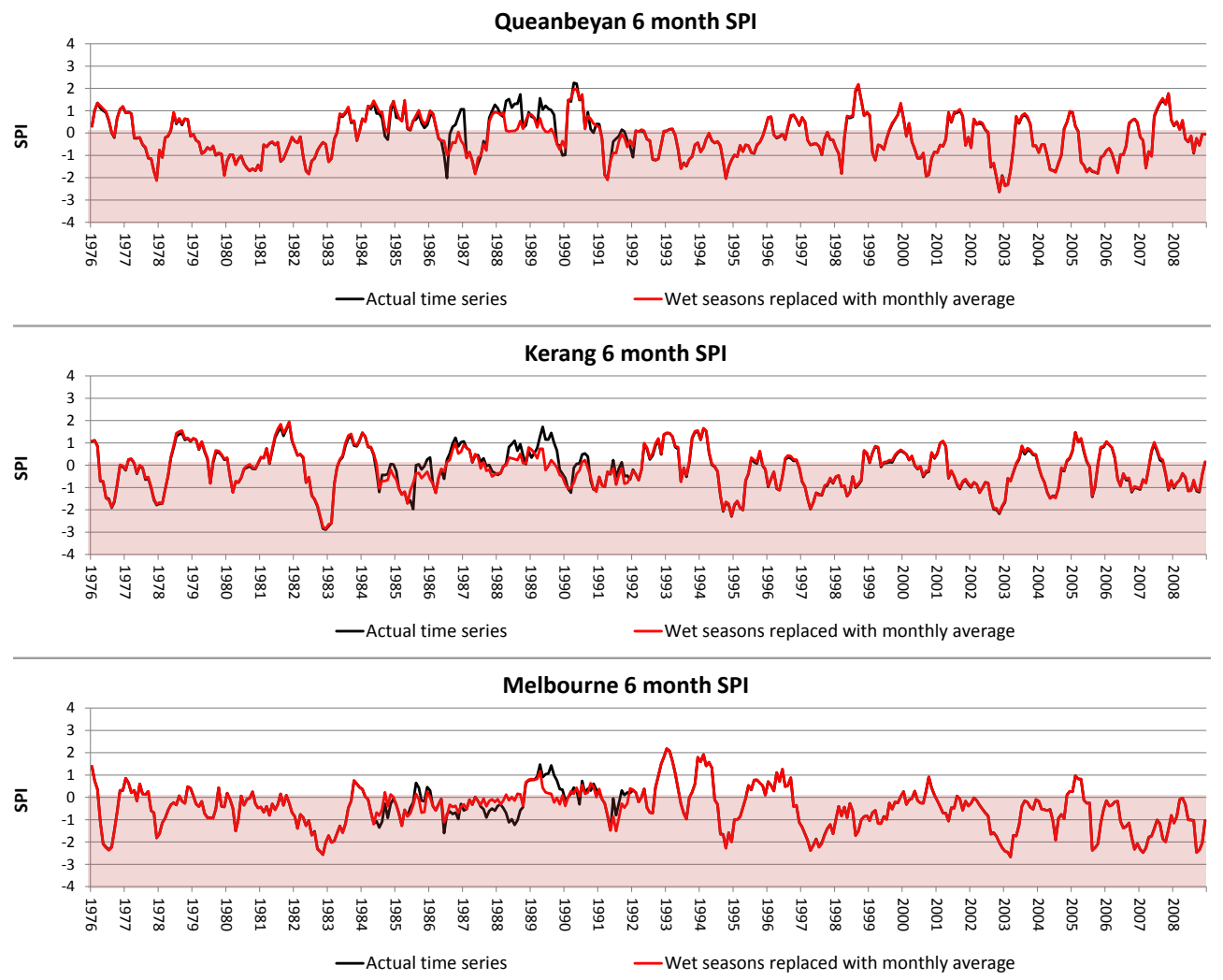

Figure 18. Monthly time series of SPI from 1976 to 2009 at Queanbeyan, Kerang and Melbourne (red shading shows SPI values that indicate dry conditions).

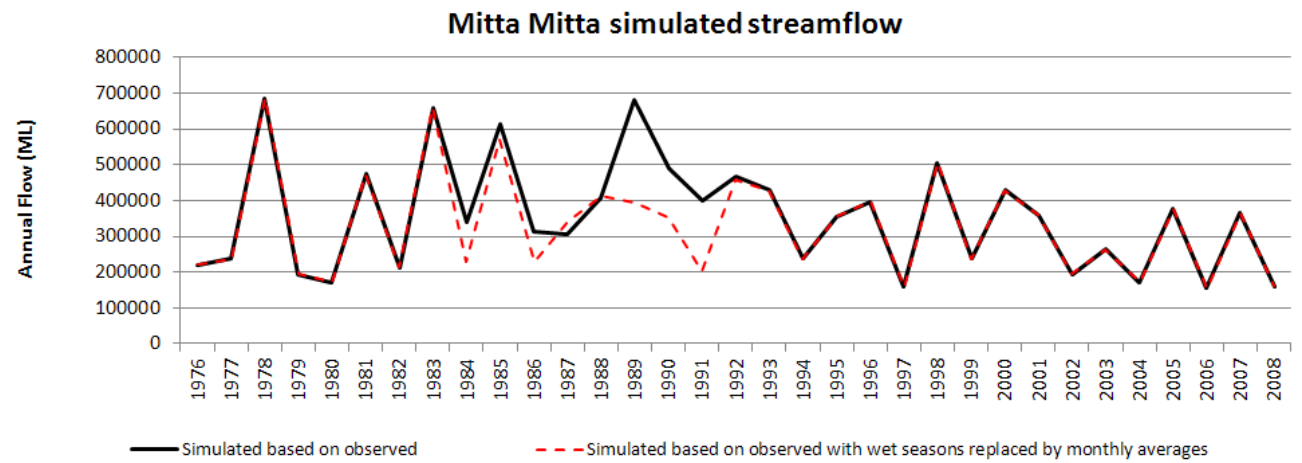

Figure 19. Monthly simulated streamflow for Mitta Mitta Creek located in Victoria, Australia.

the time for the time series with wet seasons replaced by averages. Indeed, if the rainfall had been average during these seasons, the entire period post-1982 would have been characterised by predominantly dry conditions (PDSI $<-0.5$ ).

The altered (i.e. wet winters and autumns replaced by the seasonal average) rainfall sequence for Omeo (see Figure 1 for location) was also run through a simple hydrological model (Kiem et al., 2007) to determine the impact this scenario would have on streamflow for the Mitta Mitta River (see Fig. 19). Mitta Mitta River feeds Dartmouth Dam, the largest capacity dam in Victoria, storing water for irrigation and domestic and stock use in Victoria and New South Wales. The model simulates changes in the soil moisture storage deficit over a monthly period with fluxes in rainfall, evaporation and overflow represented. A rainfall-runoff regression converts the estimated soil moisture deficit to streamflow (overall $R^{2}$ of model $=0.8$ ).

Figure 19 shows that the impacts of replacing the wet autumns/winters of the late 1980s and early 1990s with average conditions are magnified (compared to meteorological drought analysis) for streamflow. Rather than streamflow reductions occurring around the mid-1990s (as was 
experienced during the Big Dry), the streamflow simulation for Mitta Mitta River (Fig. 19) shows the possibility for streamflows to have been reduced from the mid-1980s (in the absence of the wet winter/autumns). Given the stresses placed on SEA water supply systems during the Big Dry (i.e. critical storage levels reached in $\sim 2006$ in numerous places) an extra 10 years of low streamflow would have been very challenging for water managers, bringing forward the need for the types of contingency measures that were implemented from 2006 and, potentially, further additional major system augmentations as the drought progressed.

\section{Discussion}

Based on the findings presented in this paper, we suggest that the Big Dry (or Millennium Drought) is in fact likely to be connected to the widespread Southern Hemisphere climate shift that began in the mid-1970s (also resulting in a notable decrease in SWWA winter rainfall). Since the mid-1970s there has been a general decrease in meridional winds south of 30 degrees and an increase in zonal winds, effectively shifting the storm tracks further south; hence stations located south of 45 degrees show an increase in rainfall, while mid-latitude stations have experienced a decrease in rainfall. However, the effects in SEA were shown to be masked due to smaller-scale synoptic processes which resulted in elevated autumn and winter rainfall during the mid- to late 1980s and early 1990s (a crucial period for SEA hydrology). The elevation in rainfall occurrence during this time was subsequently linked to an increased frequency of monsoon depressions and systems with strong westerly flow in autumn while, during winter, cloud band development and strong easterly flow (that would have resulted in rainfall being generated from the Pacific in the form of cut-off lows) appear to be the dominant drivers of the increased rainfall. From the mid-1990s to 2010 the frequency of these synoptic processes decreased, resulting in a return to drier than average conditions and the onset of the Big Dry.

While we have gained insight here into the synoptic processes responsible for the delayed response in the 1970s climate shift in SEA, the probability of this situation occurring needs to be established in order to properly quantify drought risk - and importantly, the chances of a drought being broken. An analysis of how the large-scale drivers (e.g. ENSO, IPO, IOD and SAM) may have influenced this period of elevated rainfall for SEA, but which was not experienced elsewhere around the Southern Hemisphere, was inconclusive. However, what was made clear from the analysis is the importance of the interaction between drivers that operate on an inter-annual to annual timescales, with the majority of elevated rainfall events occurring during periods where more than one climate mode was in its "wet" phase. It is also suggested that other large-scale processes may have played a role in the elevated rainfall period - for example upper at- mosphere phenomena such as the seasonal longwave trough (which should be the subject of future research).

Current projections for SEA are for continued drying of the region (CSIRO, 2010, 2012) primarily as a result of reduced storminess (increased stability) in the mid-latitudes in winter and a southward shift of rain-bearing systems (Frederiksen et al., 2011), along with a projected weakening and poleward expansion of the Hadley circulation ( $\mathrm{Lu}$ et al., 2007), the continuing observed trends (Lucas et al., 2012). During the 2010/11 and 2011/12 austral summer, rainfall totals were above average in SEA, breaking the long running hydrological drought. However, this rainfall was primarily tropical in origin and winter rainfall in SEA was still below average, with spring and summer being the greatest contributors to this rainfall relief. The wet spring/summer conditions were in part related to strong La Niña events in the Pacific combined, in 2010/11 only, with warm SSTs off northwestern Australia (i.e. negative IOD). Therefore, establishing the likelihood of repeat events (such as those that occurred in spring/summers of 2010/11 and 2011/12) in the next few years to decades is of crucial importance to water resource managers in the region.

\section{Conclusions and recommendations}

As discussed in Sect. 1.3, in the light of the experiences during the Big Dry and the significant uncertainties associated with future climate, changes have been made to the water management and planning framework across SEA, and also to water trading arrangements, with the aim being to better manage supplies in the face of a variable and changing climate (Moran and Sharples, 2011). The effectiveness of these planning processes would nevertheless be facilitated by better understanding the full risk profile associated with drought (that is how dry can it get and for how long). This can only be achieved by improving our understanding of the drivers of drought (both in the short- and long term) using all available information (instrumental, palaeoclimate, stochastic modelling, climate models etc.).

Finally, the findings presented here also have implications for climate change attribution studies, since many assume or aim to prove the Big Dry is due to increasing $\mathrm{CO}_{2}$ emissions. However, if this climate shift is part of a much longer (and more widespread) change in climate since the mid-1970s, the "goal post" (in terms of timing) for studies examining the potential role of $\mathrm{CO}_{2}$ (and other non- $\mathrm{CO}_{2}$ drivers) is somewhat shifted.

Acknowledgements. This study was partially funded by the Victorian Department of Sustainability and Environment (DSE) (which has subsequently become the Department of Environment and Primary Industries (DEPI)).

Edited by: M. Werner 


\section{References}

Alexander, L. V., Uotila, P., Nicholls, N., and Lynch, A.: A new daily pressure dataset for Australia and its application to the assessment of changes in synoptic patterns during the last century, J. Climate, 23, 1111-1126, doi:10.1175/2009JCLI2972.1, 2010.

Alley, W. M.: The Palmer Drought Severity Index: Limitations and Assumptions, J. Clim. Appl. Meteorol., 23, 1100-1109, 1984.

Ashok, K., Guan, Z., and Yamagata, T.: Influence of the Indian Ocean Dipole on the Australian winter rainfall, Geophys. Res. Lett., 30, 1821, doi:10.1029/2003GL017926, 2003.

Cai, W. and Cowan, T.: Dynamics of late autumn rainfall reduction over southeastern Australia, Geophys. Res. Lett., 35, L09708, doi:10.1029/2008GL033727, 2008a.

Cai, W. and Cowan, T.: Evidence of impacts from rising temperature on inflows to the Murray-Darling Basin, Geophys. Res. Lett., 35, L07701, doi:10.1029/2008GL033390, 2008b.

Cai, W., Cowan, T., and Thatcher, M.: Rainfall reductions over Southern Hemisphere semi-arid regions: the role of subtropical dry zone expansion, Scientific Reports, 2, doi:10.1038/srep00702, 2012.

Cavazos, T.: Using self-organizing maps to investigate extreme climate events: An application to wintertime precipitation in the Balkans, J. Climate, 13, 1718-1732, 2000.

Cavazos, T., Comrie, A. C., and Liverman, D. M.: Intraseasonal variability associated with wet monsoons in southeast Arizona, J. Climate, 15, 2477-2490, 2002.

Chiew, F. H. S., Piechota, T. C., Dracup, J. A., and McMahon, T. A.: El Niño Southern Oscillation and Australian rainfall, streamflow and drought - links and potential for forecasting, J. Hydrol., 204, 138-149, 1998.

CSIRO: Climate variability and change in south-eastern Australia: A synthesis of findings from Phase 1 of the South Eastern Australian Climate Initiative (SEACI), 2010.

CSIRO: Climate and water availability in south-eastern Australia: A synthesis of findings from Phase 2 of the South Eastern Australian Climate Initiative (SEACI), 2012.

DSE: Guidelines for the Development of a Water SupplyDemand Strategy, Department of Sustainability and Environment, August 2011, http://www.water.vic.gov.au/governance/ water-corporations/water-supply-demand-strategy, 2011.

Dommenget, D. and Latif, M.: A cautionary note on the interpretation of EOFs, J. Climate, 15, 216-225, 2001.

Frederiksen, J. S. and Frederiksen, C. S.: Decadal Changes in Southern Hemisphere Winter Cyclogenesis, CSIRO Marine and Atmospheric Research Paper No. 002, 35 pp., 2005.

Frederiksen, J. S. and Frederiksen, C. S.: Inter-decadal changes in Southern Hemisphere winter storm track modes, Tellus, 59, 559617, 2007.

Frederiksen C. S., Frederiksen, J. S., Sissons, J. M., and Osbrough, S. L.: Changes and projections in Australian winter rainfall and circulation: Anthropogenic forcing and internal variability, Int. J. Clim. Change Impacts Responses, 2, 143-162, 2011.

Gallant, A. J. E., Kiem, A. S., Verdon-Kidd, D. C., Stone, R. C., and Karoly, D. J.: Understanding hydroclimate processes in the Murray-Darling Basin for natural resources management, Hydrol. Earth Syst. Sci., 16, 2049-2068, doi:10.5194/hess-16-20492012, 2012.

Hewitson, B. C. and Crane, R. G.: Self-organizing maps: application to synoptic climatology, Clim. Res., 22, 13-26, 2002.
Ho, M., Kiem, A. S., and Verdon-Kidd, D. C.: The Southern Annular Mode: a comparison of indices, Hydrol. Earth Syst. Sci., 16, 967-982, doi:10.5194/hess-16-967-2012, 2012.

Hope, P. K., Drosdowsky, W., and Nicholls, N.: Shifts in the synoptic systems influencing southwest Western Australia, Clim. Dynam., 26, 751-764, 2006.

Hope, P. K., Timbal, B., and Fawcett, R.: Associations between rainfall variability in the southwest and southeast of Australia and their evolution through time, Int. J. Climatol., 30, 1360-1371, doi:10.1002/joc.1964, 2009.

$\mathrm{Hu}$, Y. and Fu, Q.: Observed poleward expansion of the Hadley circulation since 1979, Atmos. Chem. Phys., 7, 5229-5236, doi:10.5194/acp-7-5229-2007, 2007.

IOCI: Climate variability and change in south west Western Australia, Indian Ocean Climate Initiative (IOCI) Panel, Perth, Australia, 2002.

Jones, D. A., Wang, W., and Fawcett, R.: High-quality spatial climate analyses for Australia, Aust. Meteorol. Oceanogr. J., 58, 233-248, 2009.

Kiem, A. S. and Franks, S. W.: On the identification of ENSOinduced rainfall and runoff variability: a comparison of methods and indices, Hydrol. Sci. J., 46, 715-727, 2001.

Kiem, A. S. and Franks, S. W.: Multi-decadal variability of drought risk - Eastern Australia, Hydrol. Process., 18, 2039-2050, 2004.

Kiem, A. S. and Verdon-Kidd, D. C.: Towards understanding hydroclimatic change in Victoria, Australia - preliminary insights into the "Big Dry", Hydrol. Earth Syst. Sci., 14, 433-445, doi:10.5194/hess-14-433-2010, 2010.

Kiem, A. S. and Verdon-Kidd, D. C.: Steps towards "useful" hydroclimatic scenarios for water resource management in the Murray-Darling Basin, Water Resour. Res., 47, W00G06, doi:10.1029/2010WR009803, 2011.

Kiem, A. S., Franks, S. W. and Kuczera, G.: Multi-decadal variability of flood risk, Geophys. Res. Lett., 30, 1035, doi:10.1029/2002G1015992, 2003.

Kiem, A. S., Verdon, D. C., Hill, P. I., Payne, E., and Goodwin, I.: Seasonal forecasting of Victorian streamflows: Phase 1 - Identifying the drivers of Victoria's climate, Technical report prepared by Sinclair Knight Merz for the Victorian Department of Sustainability and Environment (Project: Seasonal forecasting of Victorian streamflows (VW03931)), 2007.

Lu, J., Vecchi, G. A., and Reichler, T.: Expansion of the Hadley cell under global warming, Geophys. Res. Lett., 34, L06805, doi:10.1029/2006GL028443, 2007.

Lucas, C., Nguyen, H., and Timbal, B.: An observational analysis of Southern Hemisphere tropical expansion, J. Geophys. Res., 117, D17112, doi:10.1029/2011JD017033, 2012.

Mantua, N. J., Hare, S. R., Zhang, Y., Wallace, J. M., and Francis, R. C.: A Pacific interdecadal climate oscillation with impacts on salmon production, B. Am. Meteorol. Soc., 78, 1069-1079, 1997.

McMahon, T. A., Kiem, A. S., Peel, M. C., Jordan, P. W., and Pegram, G. G. S.: A new approach to stochastically generating sixmonthly rainfall sequences based on Empirical Model Decomposition, J. Hydrometeorol., 9, 1377-1389, 2008.

Mishra, A. K. and Singh, V. P.: A review on drought concepts, J. Hydrol., doi:10.1016/j.jhydrol.2010.07.012, 2010. 
Moran, R. and Sharples, J.: Guidelines for the development of a water supply-demand strategy: Technical Supplement for Section 3.5 - Forecasting Supply, Department of Sustainability and Environment, Victoria, available at: http://www.water.vic.gov.au/_data/assets/pdf_file/ 0015/134061/Water-Supply-Demand-Strategy-Guidelines_ technical-supplement.pdf, 2011.

Murphy, B. F. and Timbal, B.: A review of recent climate variability and climate change in southeastern Australia, Int. J. Climatol., 28, 859-879, 2008.

Ngongondo, C. S.: An analysis of long-term rainfall variability, trends and groundwater availability in the Mulunguzi river catchment area, Zomba mountain, Southern Malawi, Quaternary Int., 148, 45-50, 2006.

Nicholls, N.: Local and remote causes of the southern Australian autumn-winter rainfall decline, 1958-2007, Clim. Dynam., 34, 835-845, doi:10.1007/s00382-009-0527-6, 2009.

NWC: Australia's Water Supply Status and Seasonal Outlook, National Water Commission (NWC), Canberra, ACT, 2006.

Palmer, W. C.: Meteorological Drought, US. Weather Bureau, Research Paper No. 45, 58 pp., 1965.

Pook, M. J., McIntosh, P. C., and Meyers, G. A.: The synoptic decomposition of cool-season rainfall in the southeastern Australian cropping region, J. Appl. Meteorol. Clim., 45, 1156-1170, 2006.

Power, S. and Colman, A.: Multi-year predictability in a coupled general circulation model, Clim. Dynam., 26, 247-272, 2006.

Power, S., Casey, T., Folland, C., Colman, A., and Mehta, V.: Interdecadal modulation of the impact of ENSO on Australia, Clim. Dynam., 15, 319-324, 1999.

Reusch, D. B., Alley, R. B., and Hewitson, B. C.: North Atlantic climate variability from a self-organizing map perspective, J. Geophys. Res., 112, D02104, doi:10.01029/02006JD007460, 2007.

Risbey, J. S., Pook, M. J., McIntosh, P. C., Wheeler, M. C., and Hendon, H. H.: On the remote drivers of rainfall variability in Australia, Mon. Weather Rev., 137, 3233-3253, doi:10.1175/2009MWR2861.1, 2009.

Saji, N. H., Goswami, B. N., Vinayachandran, P. N., and Yamagata, T.: A dipole mode in the tropical Indian Ocean, Nature, 401, 360363, 1999.

Salinger, M. J. and Mullan, A. B.: New Zealand climate: Temperature and precipitation variations and their links with atmospheric circulation 1930-1994, Int. J. Climatol., 19, 1049-1071, 1999.

Samuel, J. M., Verdon, D. C., Sivapalan, M., and Franks, S. W.: Influence of Indian Ocean sea surface temperature variability on Southwest Western Australia winter rainfall, Water Resour. Res., 42, W08402, doi:10.1029/2005WR004672, 2006.

Sheffield, J., Wood, E. F., and Roderick, M. L.: Little change in global drought over the past 60 years, Nature, 491, 435-438, doi:10.1038/nature11575, 2012.

Sturman, A. and Tapper, N.: The Weather and Climate of Australia and New Zealand, Oxford University Press, Melbourne, Victoria, Australia, 2004.

Tapper, N. and Hurry, L.: Australia's Weather Patterns - An Introductory Guide, Dellasta Pty Ltd, Mount Waverly, Victoria, 1996.

Thompson, D. W. J. and Wallace, J. M.: Annular modes in the extratropical circulation, part I: month-to-month variability, J. Climate, 13, 1000-1016, 2000.
Thompson, D. W. J., Wallace, J. M., and Hegerl, G. C.: Annular modes in the extratropical circulation, part II: Trends, J. Climate, 13, 1018-1036, 2000.

Timbal, B., Arblaster, J., Braganza, K., Fernandez, E., Hendon, H., Murphy, B., Raupach, M., Rakich, C., Smith, I., Whan, K., and Wheeler, M.: Understanding the anthropogenic nature of the observed rainfall decline across south-eastern Australia, The Centre for Australian Weather and Climate Research, Technical Report 026, 2010.

Tozer, C. R., Kiem, A. S., and Verdon-Kidd, D. C.: On the uncertainties associated with using gridded rainfall data as a proxy for observed, Hydrol. Earth Syst. Sci., 16, 1481-1499, doi:10.5194/hess-16-1481-2012, 2012.

Trenberth, K. E. and Guillemot, C. J.: Evaluation of the atmospheric moisture and hydrological cycle, Clim. Dynam., 14, 213-231, 1998.

Van Dijk, A. I. J. M., Beck, H. E., Crosbie, R. S., de Jeu, R. A. M., Liu, Y. Y., Podger, G. M., Timbal, B., and Viney, N. R.: The Millennium Drought in southeast Australia (2001-2009): Natural and human causes and implications for water resources ecosystems, economy, and society, Water Resour. Res., 49, 1040-1057, doi:10.1002/wrcr.20123, 2013.

Van Ommen, T. D. and Morgan, V.: Snowfall increase in coastal East Antarctica linked with southwest Western Australian drought, Nat. Geosci., 3, 267-272, doi:10.1038/NGEO761, 2010.

Verdon, D. C. and Franks, S. W.: Indian Ocean sea surface temperature variability and winter rainfall: Eastern Australia, Water Resour. Res., 41, W09413, doi:10.1029/2004WR003845, 2005.

Verdon, D. C. and Franks, S. W.: Long-term behaviour of ENSO: Interactions with the PDO over the past 400 years inferred from paleoclimate records, Geophys. Res. Lett., 33, L06712, doi:10.1029/2005GL025052, 2006.

Verdon-Kidd, D. C. and Kiem, A. S.: Nature and causes of protracted droughts in southeast Australia: Comparison between the Federation, WWII, and Big Dry droughts, Geophys. Res. Lett., 36, L22707, doi:10.1029/2009GL041067, 2009a.

Verdon-Kidd, D. C. and Kiem, A. S.: On the relationship between large-scale climate modes and regional synoptic patterns that drive Victorian rainfall, Hydrol. Earth Syst. Sci., 13, 467-479, doi:10.5194/hess-13-467-2009, 2009 b.

Verdon-Kidd, D. C. and Kiem, A. S.: Quantifying drought risk in a non-stationary climate, J. Hydrometeorol., 11, 1020-1032, 2010.

Verdon-Kidd, D. C. and Kiem, A. S.: Synchronicity of historical dry spells in the Southern Hemisphere, Hydrol. Earth Syst. Sci., 18, 2257-2264, doi:10.5194/hess-18-2257-2014, 2014.

Verdon, D. C., Wyatt, A. M., Kiem, A. S., and Franks, S. W.: Multidecadal variability of rainfall and streamflow - Eastern Australia, Water Resour. Res., 40, W10201, doi:10.1029/2004WR003234, 2004.

Whan, K., Timbal, B., and Lindsay, J.: Linear and nonlinear statistical analysis of the impact of sub-tropical ridge intensity and position on south-east Australian rainfall, Int. J. Climatol., 34, 326-342, doi:10.1002/joc.3689, 2014. 